\title{
Gisele Levy
}

Uso e seleção de habitat por Saltator atricollis (Aves

Cardinalidae) e Cypsnagra hirundinacea (Aves Thraupidae) no

Cerrado da Estação Ecológica de Itirapina, São Paulo.

São Paulo

2009 


\section{Gisele Levy}

Uso e seleção de habitat por Saltator atricollis (Aves

Cardinalidae) e Cypsnagra hirundinacea (Aves Thraupidae) no

Cerrado da Estação Ecológica de Itirapina, São Paulo.

Dissertação apresentada ao Instituto de Biociências da Universidade de São Paulo, para obtenção de título de Mestre em Ciências, na área de Ecologia.

Orientador: Prof. Dr. José Carlos Motta Junior

São Paulo

2009 
Levy, Gisele

Uso e seleção de habitat por Saltator atricollis (Aves Cardinalidae) e Cypsnagra hirundinacea (Aves, Thraupidae) no Cerrado da Estação Ecológica de Itirapina, São Paulo.

57 páginas

Dissertação (Mestrado) - Instituto de Biociências da Universidade de São Paulo. Departamento de Ecologia.

1. Uso de habitat 2. seleção 3.micro-habitat. I. Universidade de São Paulo. Instituto de Biociências. Departamento de Ecologia.

Comissão Julgadora:

Prof. Dr. José Carlos Motta Junior

Orientador 
Dedico ao meu querido avô Joseph (in memoriam) pelas lições de vida e por todo amor dedicado e a minha amada avó Laís (in memoriam) por todo carinho. 
Primeiramente quero agradecer aos meus pais por todo amor, carinho, apoio, por sempre respeitarem todas as minhas escolhas e por todos os ensinamentos e paciência ao logo de toda minha vida.

Ao prof. José Carlos Motta Junior pela orientação, apoio e atenção durante todo o período do mestrado e também pelas boas fotos cedidas.

Ao Victor Nakama por ter me incentivado desde o início nessa nova empreitada, pelos livros de estatística e é claro por todo carinho e dedicação que tem me dado.

Aos meus irmãos simplesmente por fazerem parte da minha vida, me trazerem tão boas recordações e por eu saber que sempre posso contar com eles para tudo, em especial ao meu irmão Ivo pela preocupação e atenção nessa fase do mestrado e por sempre me ouvir nas horas em que precisei.

Às amigas Gabriella Fuser e Nellysye pelo apoio em alguns momentos dificeis e pelas saidas para relaxar.

À Mieko F Kanegae pela grande amiga que se tornou, por todo apoio e aventuras no campo e no laboratório, pelas conversas sobre o projeto, pela importante ajuda na revisão da dissertação e pelos bons momentos em Itirapina.

Ao Marco Antônio Granzinolli pelas sugestões no artigo de qualificação, e pelas boas conversas nos almoços e cafezinhos.

Ao Dárius Tubellis pelas valiosas sugestões e correções durante o período de qualificação.

À Fabiana Pioker pela amizade, pela companhia no curso de ecologia de campo pela ajuda durante a qualificação, pela companhia em Itirapina tanto no campo como nos sorvetes.

Aos professores Roberto M Shimizu, Márcio R C Martins, Pérsio S Santos-Filho e Sérgio Rosso por terem feito importantes sugestões durante a banca de qualificação.

Aos amigos de Itirapina, Maria Viana, Roberto G Tovati, Matheus Reis, Hipólito Neto pelos bons dias de campo no cerrado, pelos almoços comunitarios no alojamento, risadas e festinhas.

A Marina Telles pela amizade, por me emprestar o carro no campo, pelas boas conversas e risadas em Itirapina e pela companhia nos shows e saídas em São Carlos. 
Aos professores e companheiros do curso de Ecologia de campo principalmente a Andrea, Denise, Victor e Marcia que se tornaram bons amigos.

Aos meus ajudantes de campo Arina, Igor e Renan pela disposição e alegria em campo, por aguentarem firmemento os dias de calor e algumas vezes de chuva fazendo o trabalho ser mais animado e agradável.

À Ana Claudia Braga pelo apoio após a qualificação e pelas sugestões na dissertação.

À minha grande amiga e irmã de coração Audrey pela amizade durante toda a vida, pela ajuda com as traduções e pelas conversas e desabafos.

Aos, a princípio, amigos do Victor e que hoje considero meus amigos Fernado e Mari por emprestarem a sua casa onde pude estudar e dar início a essa empreitada.

À Camila Mandai pela tarde de conversa e reflexões sobre regresão logística.

À Simone Freitas pelos ensinamentos de como usar o programa "r" e como rodar a regressão logística.

Ao Breno Colares pela a ajuda de última hora com a tradução do resumo.

À Socorro, Bernadete e em especial a Dalva pela atenção, carinho e disposição em ajudar com todas as dúvidas e problemas burocráticos.

Ao Wellington Bispo e ao Luís por ajudarem com a instalação de programas, problemas com computadores e paciência em ensinar a utilizar alguns programas.

A todos os funcionários da Estação Ecológica de Itirapina que permitiram a realização desse trabalho, em especial ao Gilson, Chico e Paulo (Parada louca) por facilitarem o trabalho, por me socorrerem nos momentos de atolamento independente do dia da semana e horário e por sempre fornecerem as informações solicitadas.

Ao pessoal da oficina do Manduca sempre tão prestativo nas horas em que o carro já não aguentava mais ir ao campo e precisava dar uma arrumadinha.

À querida Isabel, funcionária do alojamento em Itirapina, por sempre se preocupar em deixar tudo em ordem no alojamento e sempre dar um jeitinho para nos instalar e em especial pelo carinho, conversas descontraidas e pelos pães e presentinhos, guardados com muito carinho.

Ao departamento de Ecologia, principalmente a professora Astrid pelo auxílio no mestrado e apoio financeiro em campo e no congresso de Ornitologia.

Ao CNPq pela bolsa de mestrado. 
À Idea Wild, Neotropical Grassland Conservancy - W.J. and Virginia W. Moorhouse Memorial Grant pelo apoio financeiro e pela doação de equipamentos.

Finalmente quero agradecer e me desculpar a todos aqueles que não me lembrei de citar, mas que de alguma forma me ajudaram a chegar até aqui e tornar possível concluir mais essa etapa na minha vida.

Muito obrigada!!! 


\section{ÍNDICE}

RESUMO

1. INTRODUÇÃO 3

1.10 Cerrado e sua avifauna 3

$\begin{array}{ll}1.2 \text { Uso e seleção de habitat } & 4\end{array}$

2. MATERIAL E MÉTODOS 13

2.1 Área de estudo $\quad 13$

2.2 Coleta de dados 19

2.2.1 Amostragem das aves 19

2.2.2 Uso e seleção de macro-habitat 20

2.2.3 Uso e seleção de micro-habitat 23

3. RESULTADOS

$\begin{array}{ll}3.1 \text { Uso e seleção de macro-habitat } & 27\end{array}$

3.2 Uso e seleção de micro-habitat 28

4. DISCUSSÃO 31

4.1 Uso e seleção de macro-habitat 31

4.2 Uso e seleção de micro-habitat 33

5. REFERÊNCIAS BIBLIOGRÁFICAS

ANEXO 1: Tabela com teste de Mann-Whitney $\quad 49$ 


\section{Resumo}

Os estudos sobre a relação habitat-espécie são importantes para a conservação, pois geram conhecimento sobre características de habitat essenciais para uma população. A incorporação destas informações em planos de conservação permite um manejo mais inteligente tanto da fauna como das áreas a serem preservadas. O presente estudo teve como objetivo estudar o uso e a seleção de habitat de Saltator atricollis e Cypsnagra hirundinacea na Estação Ecológica de Itirapina, região central do estado de São Paulo, Brasil. Ambas espécies são aves endêmicas do Cerrado e ameaçadas de extinção no Estado de São Paulo. O estudo foi desenvolvido entre setembro e dezembro de 2007 e setembro de 2008. O habitat foi analisado em duas escalas: o macro-habitat e o micro-habitat. Para analisar o habitat foram dispostos sistematicamente 84 pontos de amostragem na área de estudo. Na análise do macro-habitat foram utilizadas informações sobre o usodisponibilidade das diferentes fisionomias sendo comparadas por meio do intervalo de confiança de Bailey. No estudo de micro-habitat foram medidas 11 características estruturais da vegetação ao redor de cada ponto de contato com $S$. atricollis, com $C$. hirundinacea e nos 84 pontos de amostragem. Para analisar as associações entre as características estruturais e as aves foi utilizado modelos de regressão logística selecionados pelo Critério de Informações de Akaike (AIC). Saltator atricollis selecionou áreas de campo cerrado, utilizou na mesma proporção que o esperado as áreas campestres e utilizou menos que o esperado o cerrado sensu stricto. Cypsnagra hirundinacea utilizou na mesma proporção que o esperado as áreas campestres e o campo cerrado enquanto o cerrado sensu stricto foi utilizado menos que o esperado. Quanto ao micro-habitat os melhores modelos para explicar a presença de $S$. atricollis incluíram maior densidade de árvores maiores que $2 \mathrm{~m}$ de altura e menor densidade de Syagrus petrea e de arbustos com até $1 \mathrm{~m}$ de altura. A presença de árvores é importante para a espécie, pois são utilizadas como poleiros durante o comportamento de sentinela. As altas densidades de Syagrus petrea e arbustos baixos $(<1 \mathrm{~m})$ podem diminuir a quantidade de moitas de gramíneas (utilizadas para a construção de ninhos) já que ambos ocupam o mesmo estrato. Assim, indiretamente, a presença de Syagrus petrea e arbustos baixos $(<1 \mathrm{~m})$ podem diminuir a disponibilidade de sítios reprodutivos. Além disso, podem atrapalhar o forrageamento por dificultar a utilização do estrato herbáceo. Os modelos que explicaram melhor a presença de $C$. hirundinacea foram representados por uma maior densidade de arbustos e árvores intermediárias e altas (entre 1 e $2 \mathrm{~m}$, entre 2 e $4 \mathrm{~m}$ e maiores que $4 \mathrm{~m}$ de altura), maior densidade de braquiária e menor densidade de Attalea geraensis e de solo exposto. A presença de árvores é importante, pois a espécie as usa para forragear, construir ninhos e vigiar contra predadores. A relação positiva com a braquiária pode estar relacionada ao fato da espécie não utilizar o estrato herbáceo e ao mesmo tempo a invasão dessa gramínea, possivelmente, ainda não deve ter alterado a estrutura da vegetação lenhosa. Já a relação inversa entre a presença de $C$. hirundinacea e a densidade de solo exposto e de A. geraensis deve ocorrer, pois em ambientes com alta densidade dessas variáveis provavelmente há um baixo número de árvores o que diminui a disponibilidade de sítios de forrageamento e reprodutivos. Portanto para a manutenção dessas espécies é importante preservar as fisionomias abertas do Cerrado, as quais estão desaparecendo no estado de São Paulo, além disso recomenda-se manter nessas fisionomias a presença de algumas árvores e evitar a dominância de palmeiras rasteiras.

Palavras-chave: Uso de habitat, seleção de habitat, Cerrado, Saltator atricollis, Cypsnagra hirundinacea 


\begin{abstract}
Habitat use and section by Saltator atricollis (Aves, Cardinaliae) and Cypsnagra hirundinacea (Aves, thraupidae) in the cerrado of Estação Ecológica de Itirapina, southeastern Brazil.
\end{abstract}

Studies about habitat-species relationships are important for conservation, because they generate knowledge about the essential characteristics of a habitat for a population. Incorporation of such information in conservation plans allows for a more intelligent management of both fauna and habitats that should be preserved. The aim of this study was to investigate the habitat use and selection by Saltator atricollis and Cypsnagra hirundinacea at Estação Ecológica de Itirapina in central State of São Paulo, Brazil. Both species are endemic birds of the Cerrado (Brazilian Savannah) and they are considered threatened with extinction in the State of São Paulo. The study was developed from September to December of 2007 and in September 2008. Habitat was analyzed in two scales: macrohabitat and microhabitat. To analyze the habitat 84 sampling points had been distributed at the study area. Macrohabitat selection was analyzed based on use-availability data of physiognomy and performing Bailey's confidence interval. To investigate the use of the microhabitat there were estimated eleven structural characteristics of vegetation. These characteristics were described in each exact point that $S$. atricollis and $C$. hirundinacea had seen and in the 84 sampling points. The associations between the structural characteristics and the birds were identified by logistic regression models selected by Akaike Information Criteria (AIC). Saltator atricollis selected "campo cerrado" physiognomies (grassland savannah), it use "campos" (grasslands) at the expected proportion and "cerrado sensu stricto" (woodland savannah) less than expected proportion. Cypsnagra hirundinacea used both "campos" and "campo cerrado" areas at expected proportions while "cerrado sensu stricto" was used less than expected proportion. At the microhabitats level, the best models to explain the presence of $S$. atricollis included greater density of trees higher than 2 meters, lesser density of Syagrus petrea, and lesser density of bushes of to up to 1 meter height. The presence of trees is important to this specie, because the trees are used as perches during sentinel behavior. The high density of Syagrus petrea should diminish the amount of grassy because they use the same space on the habitat. Birds use the grassy to make its nest and the presence of Syagrus petrea and short bushes $(<1 \mathrm{~m})$ should indirectly reduce places for reproductive sites and might make foraging more difficult. The best models to explain the presence of $C$. hirundinacea were the one represented by a greater density of bushes and, trees of intermediate to greater height (between 1 and 2 meters, between 2 and 4 meters, and higher than 4 meters), greater density of Brachiaria grasses and lesser density of Attalea geraensis and exposed ground. The presence of trees is important because the species use them to forage, build nests and watch against predators. The positive relation with Brachiaria grasses might be occurs because $C$. hirundinacea don't use the herb layer. Possibly, the invasion of the Brachiaria grasses not having changed the structure of the vegetation yet. The inverse relation between the bird specie and the presence of exposed ground and $A$. geraensis, should occur because in habitats with high density of exposed ground and A. geraensis there are few places to feed and to reproduction. Therefore, to the maintenance of these birds' species it is important preserving the open physiognomies of the Cerrado, which are disappearing from the State of São Paulo. It's also necessary to keep in theses physiognomies the presence of a few bushes and trees and also avoid the dominance of A. geraensis and Syagrus petrea.

Key-word: Habitat-use, habitat-selection, Cerrado, Black-throated Saltator, White-rumped Tanager, Brasilian savannah. 


\section{INTRODUÇÃO}

\subsection{O Cerrado e sua avifauna}

O Cerrado é o segundo maior bioma brasileiro, o qual ocupa uma área de aproximadamente dois milhões de quilômetros quadrados (RATTER et al., 1997). Além disso, é provavelmente a savana tropical mais ameaçada do mundo (SILVA, 2002). Segundo Machado et al. (2004) até o ano de 2002 cerca de 55\% da área ocupada pelo Cerrado já havia sido desmatada, principalmente para a formação de pastagens e culturas agrícolas. Estimativas indicam que a perda anual causada pelo desmatamento no Cerrado corresponde a 22 milhões de hectares (MACHADO et al., 2004). Com a crescente devastação, informações valiosas sobre a história e biodiversidade do Cerrado vêm sendo perdidas sem que possam ser recuperadas posteriormente (RODRIGUES, 2005).

As transformações ocorridas nesse bioma causaram danos ambientais como fragmentação de habitats, diminuição da biodiversidade, invasão de espécies exóticas, erosão dos solos, poluição dos aqüíferos, degradação de ecossistemas, alterações nos regimes de queimadas, desequilíbrio no ciclo de carbono e possivelmente modificações climáticas regionais (KLINK \& MACHADO, 2005).

A biodiversidade é alta, mas vem sendo menosprezada. O endemismo da flora é elevado com aproximadamente $44 \%$ das plantas sendo representada por espécies endêmicas o que torna esse bioma a savana tropical mais diversa do mundo (KLINK \& MACHADO, 2005). O cerrado está entre os 25 "hotspots" mundiais de biodiversidade, ou seja, área com alto número de espécies endêmicas e que sofre uma excepcional perda de habitat (MYERS et al., 2000). Com relação à avifauna, esta é rica possuindo aproximadamente 856 espécies (SILVA \& SANTOS, 2005), porém o nível de endemismo é baixo (MYERS et al., 2000). 
Há um total de 36 espécies endêmicas, ou seja, 4,3\% do total das espécies (CAVALCANTI 1999, BAGNO \& MARINHO-FILHO 2001, SILVA \& SANTOS 2005, MARINI \& GARCIA, 2005).

A situação do Cerrado no estado de São Paulo é ainda mais crítica. Originalmente $14 \%$ do estado eram ocupados por áreas de cerrado, mas com o intenso desmatamento para a implantação de culturas e pastagens esta porcentagem caiu para menos de $1 \%$ espalhados em fragmentos na maioria muito pequenos (Secretaria do Meio Ambiente de São Paulo, 1997; DURIGAN et al. 2004). Mesmo apresentando tamanhos reduzidos, estes fragmentos ainda são capazes de manter diversas espécies de aves ameaçadas funcionando como último refúgio para muitas delas (DIAS, 2000; DEVELEY et al., 2005; MOTTA-JUNIOR et al. 2008).

Portanto, devido ao alto grau de devastação e a presença de espécies dependentes dos remanescentes de cerrado, a conservação destes no estado de São Paulo torna-se de suma importância.

\subsection{Uso e seleção de habitat}

O termo "habitat" muitas vezes é usado de forma ambígua devido às diversas terminologias que pode assumir (BLOCK \& BRENAN, 1993) e por isso, termos como "uso de habitat" e "seleção de habitat" podem não ser claramente definidos (JONES, 2001). O conceito sobre uso de habitat está relacionado com a utilização de um habitat por uma espécie em uma determinada região. A seleção de habitat considera as variações na abundância/densidade de uma espécie entre diferentes tipos de habitat (SUTHERLAND \& GREEN, 2008).

A seleção de habitat é uma resposta comportamental inata ou aprendida por uma ave que a permite distinguir entre diversos componentes do meio ambiente resultando em 
um uso desproporcional destes. A escolha diferenciada de habitats ou estruturas específicas presentes em um local irá influenciar na sobrevivência e na aptidão do indivíduo (BLOCK \& BRENAN, 1993).

Portanto a seleção sugere uma preferência do animal em usar mais um habitat do que o outro, enquanto o uso constata apenas a presença/ocupação da espécie no habitat sem considerar a disponibilidade do mesmo. É preciso ter cuidado ao se falar em seleção, pois diferenças na utilização não implicam necessariamente em seleção, visto que um habitat muito abundante e menos preferido pode ser mais utilizado em relação a um raro e preferido. Por este motivo, ao se analisar a seleção, é preciso considerar a disponibilidade de cada tipo de habitat na área estudada (SUTHERLAND \& GREEN, 2008).

O uso e a seleção de habitat por uma espécie podem ser influenciados por diversos fatores tais como, a estrutura da vegetação, a composição florística, os recursos alimentares e o micro-clima (ROTENBERRY, 1985; WIENS, 1989). Além disso, relações intra e interespecíficas e fatores populacionais também influenciam as espécies quanto ao uso e seleção de uma determinada área (WIENS, 1989). Geralmente, para as aves campestres, os fatores que mais influenciam o uso de habitat são a altura e estrutura da vegetação, a quantidade de serapilheira e a quantidade de solo exposto (AUSDEN, 2008).

Diferentes escalas podem ser utilizadas no estudo de uso e seleção de habitat (HUTTO, 1985; BLOCK \& BRENAN, 1993). A maior delas, chamada de macro-habitat ou simplesmente de habitat (KRAUSMAN, 1999; BIBBY, 2001) considera a seleção da paisagem geográfica, como por exemplo, as fisionomias de uma região. Outra escala um pouco mais restrita está relacionada com a área de vida do animal. Enquanto a menor escala, conhecida como micro-habitat corresponde às áreas específicas de utilização como locais para ninho, forrageamento, proteção contra predadores (KRAUSMAN, 1999). 
Além de se considerar a escala, há três abordagens possíveis para se avaliar a seleção (GARSHELIS, 2000): A primeira chamada de use-availability design compara o número de encontros do animal estudado em cada habitat disponível com a área relativa destes habitats; a segunda, site attribute design, compara componentes presentes em áreas específicas usadas pelo animal com áreas não usadas ou distribuídas aleatoriamente no local de estudo; e a terceira, demographic response design, compara os aspectos demográficos (densidade, reprodução e sobrevivência) dos animais em diferentes habitats. Nas duas primeiras abordagens a qualidade ou importância do habitat é investigada a partir de uma medida comparativa de vários habitats ou componentes dos mesmos podendo assim ser inferida como uma seleção (mesmo que aparente). Já a terceira abordagem tem sido utilizada para correlacionar o animal com um determinado habitat, não sendo, portanto uma medida direta de seleção (GARSHELIS, 2000).

Muitos estudos sobre o uso e/ou seleção de habitat analisam o tipo de paisagem e/ou componentes específicos da vegetação que importam para a ocorrência das espécies (e.g. DYKSTRA et al., 2001; CANAVELLI et al., 2003; BORGUHESIO \& LAIOLO, 2004; PATTEN et al., 2005; SCHLOSSBERG, 2006; CONWAY \& SULZMAN, 2007). No Brasil, poucos estudos abordaram a seleção de componentes dos habitats (e.g. MARSDEN et al., 2000; POLETTO et al., 2004; FAVARO \& ANJOS, 2005; LOPES et al., 2006; KANEGAE, 2009).

Os estudos sobre a relação habitat-espécie são importantes para a conservação, pois geram conhecimento sobre características de habitat essenciais para uma população. A incorporação destas informações em planos de conservação permite um manejo mais inteligente tanto das espécies como das áreas a serem preservadas (WIENS \& ROTENBERRY, 1981; CAUGHLEY, 1994). Mesmo com um grande valor para a 
conservação das espécies e dos habitats, esses estudos são em pequeno número no bioma Cerrado (e.g. TUBELIS \& CALVALCANTI, 2001; LOPES \& MARINI, 2006; KANEGAE, 2009; GRANZINOLLI, 2009). A maioria dos estudos aborda as taxocenoses de aves e apenas relata sucintamente o habitat utilizado pelas espécies (e.g. WILLIS \& ONIKI, 1981; MOTTA-JUNIOR \& VASCONCELLOS, 1996; SILVA, 1995; DIAS, 2000; TUBELIS \& CALVALCANTI, 2000; BAGNO \& MARINHO-FILHO, 2001; WILLIS, 2004; DEVELEY et al., 2005; MOTTA-JUNIOR et al. 2008).

Além disso, de maneira geral, informações básicas a respeito da biologia e ecologia de muitas espécies de aves do Cerrado são escassas ou ainda não existem (MARINI \& GARCIA, 2005). Das 36 espécies de aves endêmicas (CAVALCANTI, 1999), apenas seis foram alvo de pesquisa de campo por um período igual ou superior a 1 ano (MARINI \& GARCIA, 2005).

Estudar espécies endêmicas é importante para a conservação, pois permite conhecer a ecologia e biologia de tais espécies que são dependentes de um ambiente específico. Ao se pesquisar sobre o uso e seleção de habitat de espécies endêmicas é possível descobrir requisitos essenciais para a manutenção da espécie e ao mesmo tempo preservar um habitat único.

O bico-de-pimenta, Saltator atricollis Vieillot, 1817 (Cardinalidae) e a bandoleta, Cypsnagra hirundinacea (Lesson, 1831) (Thraupidae) são aves endêmicas do Cerrado (CAVALCANTI, 1999; BAGNO \& MARINHO-FILHO, 2001) e ameaçadas de extinção no estado de São Paulo devido principalmente a perda de habitat (SÃO PAULO, 2008). São aves de fácil detectabilidade visual e auditiva, e com poucas informações sobre suas biologia e ecologia o que as torna um bom instrumento de estudo. 
Saltator atricollis (Figura 1) é considerada ameaçada de extinção segundo a Lista das Espécies da Fauna Ameaçada de Extinção no Estado de São Paulo (SÃO PAULO, 2008). Está classificada na categoria vulnerável (VU), ou seja, espécies que apresentam alto risco de extinção em médio prazo, devido a alterações ambientais preocupantes ou da redução populacional ou ainda devido a grande diminuição da área de distribuição do táxon (SÃO PAULO, 2008). É uma espécie com média sensibilidade a distúrbios antrópicos e média prioridade para a conservação (STOTZ et al., 1996).

Este representante da família Cardinalidae é encontrado nas paisagens abertas do Cerrado (SICK, 1997; RAGUSA-NETTO, 2001) e também na borda de pastos sujos (WILLIS \& ONIKI, 2003). Vive em grupos familiares de dois a seis indivíduos e participa de bandos mistos. Normalmente, um indivíduo fica empoleirado em uma árvore exercendo a função de sentinela, vigiado contra possíveis ataques de predadores aéreos enquanto o restante do grupo forrageia no capim, no chão ou na base de arbustos (RAGUSA-NETTO, 2001; WILLIS \& ONIKI, 2003). Ocorre no interior nordeste e central do Brasil, no sul do Maranhão e Ceará até Minas Gerais, Mato Grosso, e São Paulo. Também ocorre na Bolívia e Paraguai (RIDGELY \& TUDOR, 1994). Recentemente foi registrado pela primeira vez no estado de Pernambuco (TELINO-JUNIOR et al., 2008).

Cypsnagra hirundinacea (Figura 2) também está ameaçada de extinção segundo a Lista das Espécies da Fauna Ameaçada de Extinção no Estado de São Paulo (SÃO PAULO, 2008). Está classificada na categoria em perigo (EP), ou seja, espécies que apresenta risco de extinção em futuro próximo devido a grades alterações ambientais preocupantes, ou significativa redução populacional ou ainda devido a grande diminuição da área de distribuição do táxon (SÃO PAULO, 2008). Apresenta alta sensibilidade a distúrbios antrópicos e média prioridade de conservação (STOTZ et al., 1996). 
Cypsnagra hirundinacea habita áreas do cerrado com árvores e arbustos dispersos, sendo encontrada em áreas de Cerrados contínuos ou isolados (RIDGELY \& TUDOR, 1989; SICK, 1997). Usualmente ocorre em grupos de dois a oito indivíduos, participa de bandos heteroespecificos e pode exercer a função de sentinela (RAGUSA-NETTO, 1997; WILLIS \& ONIKI, 2003). Forrageia normalmente na folhagem de árvores e arbustos, mas no período de seca passa a utilizar as cascas das árvores para a procura de alimento e raramente desce ao solo (RAGUSA-NETTO, 1997). Sua distribuição, muitas vezes se sobrepõe com a de S. atricollis, ocorrendo no nordeste do Brasil até Minas Gerais, Mato Grosso, Goiás, São Paulo e Paraná. Também ocorre na Bolívia e no Paraguai (RIDGELY \& TUDOR 1989, SICK 1997).

Ambas espécies são classificadas como independentes de florestas, ou seja, associadas às fisionomias não florestais do Cerrado (SILVA, 1995), são bioindicadoras de qualidade ambiental e potencialmente dispersoras de sementes(BAGNO \& MARINHOFILHO, 2001). As espécies são observadas juntas formando bandos mistos (RAGUSANETTO, 2000) o que explica a similaridade na classificação e distribuição das mesmas.

Dados sobre uso de habitat dessas espécies podem ser encontrados dispersos em estudos mais gerais sobre taxocenoses de aves. Nesses estudos $S$. atricollis e $C$. hirundinacea foram registrados utilizando as fisionomias de campo sujo e campo cerrado (MOTTA-JUNIOR et al. 2008) e S. atricollis em áreas de cerrado sensu stricto (TUBELIS \& CALVALCANTI, 2001).

Apesar de serem espécies consideradas relativamente comuns (RIDGELY \& TUDOR, 1989), em Minas Gerais, na região baixa do Parque da Serra do Cipó, a frequência de ocorrência foi baixa para ambas. Saltator atricollis apresentou uma frequência variando entre 25 e $49 \%$ e Cypsnagra hirundinacea foi ainda mais incomum, 
com frequência menor que 5\% (RODRIGUES et al., 2005). Porém os estudos acima citados não informam sobre a seletividade de habitat nem sobre as características do microhabitat utilizado.

Um estudo realizado na Estação Ecológica de Itirapina com sete espécies de aves endêmicas do Cerrado (KANEGAE, 2009) estimou o tamanho populacional de S. atricollis em aproximadamente 130 indivíduos e ao se observar a densidade em diferentes habitats a espécie foi mais comum no campo cerrado. Cypsnagra hirundinacea apresentou um tamanho populacional de aproximadamente 142 indivíduos e densidade similar entre habitats campestres e campo cerrado.

Tendo em vista o exposto a cima, o presente estudo objetivou responder as seguintes questões:

1) Saltator atricollis e Cypsnagra hirundinacea utilizam as diferentes fisionomias de cerrado de acordo com a sua disponibilidade?

2) Quais componentes da estrutura da vegetação são importantes para as espécies?

3) A presença de gramíneas exóticas inibe a ocorrência das espécies?

Essas informações irão contribuir para o conhecimento da ecologia das espécies e poderão servir de subsídios em planos de manejo e conservação tanto destas aves como do Cerrado. 

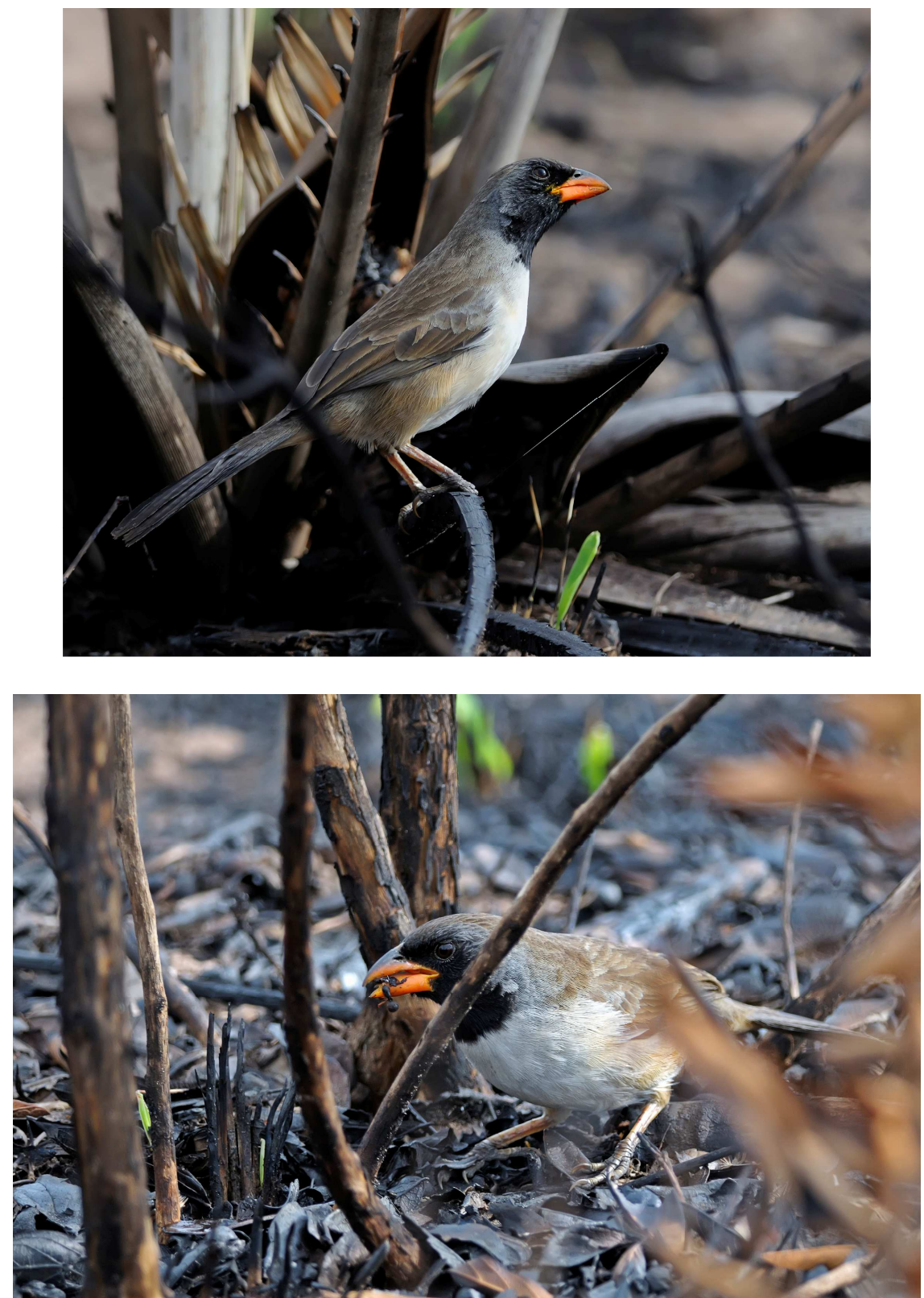

Figura 1: Saltator atricollis forrageando próximo do chão (acima) e no chão (abaixo) de área recentemente queimada em julho 2009. (Fotos: José Carlos Motta-Junior) 

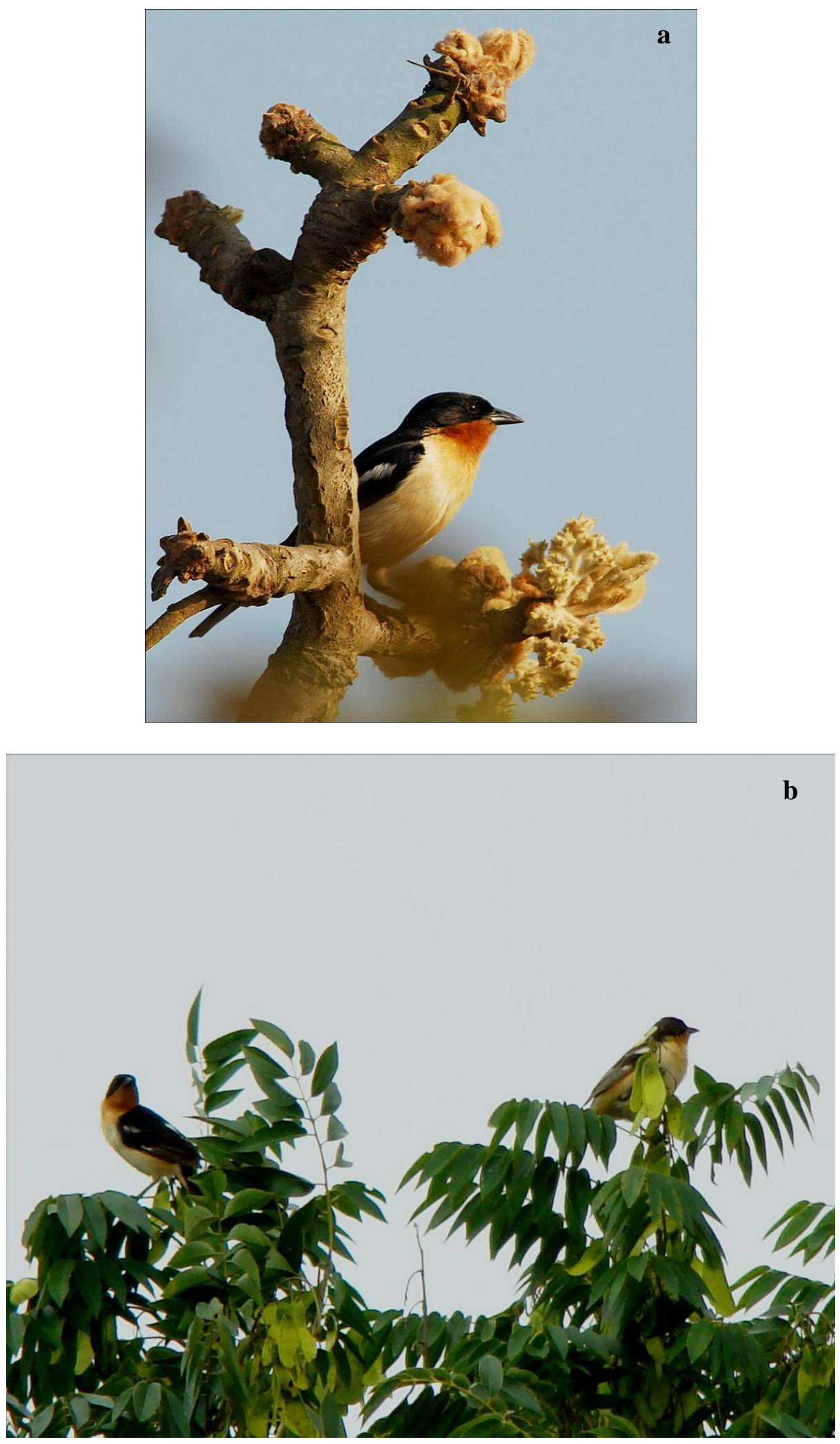

Figura 2: Cypsnagra hirundinacea(Fotos: a - José Carlos Motta-Junior, b - Gisele Levy). 


\section{MATERIAL E MÉTODOS}

\section{1 Área de estudo}

O estudo foi conduzido na Estação Ecológica de Itirapina (EEI), pertencente ao Instituto Florestal do Estado de São Paulo e localizada nos municípios de Brotas e Itirapina $\left(22^{\circ} 13^{\prime}\right.$ S e $\left.47^{\circ} 53^{\prime} \mathrm{W}\right)$, região central do estado de São Paulo. Sua área total é de aproximadamente 2.700 ha, com altitude entre 720 e $750 \mathrm{~m}$ fazendo parte do Domínio Cerrado. As diferentes fitofisionomias deste Domínio, bem como áreas alteradas em recuperação, áreas de brejos e matas de galeria estão representadas dentro dos limites da estação (MANTOVANI 1985, BRASILEIRO et al. 2005) (Figura 3).

O clima da região é do tipo mesotérmico (ou Cwa de Koeppen) com uma estação seca bem definida ocorrendo de abril a setembro com pluviosidade média mensal de 44,2mm. A estação chuvosa ocorre entre outubro e março, com pluviosidade média mensal de $191,2 \mathrm{~mm}$. Durante a estação seca, as temperaturas mínimas variam entre 0 e $11^{\circ} \mathrm{C}$ e as temperaturas máximas entre 28 e $36^{\circ} \mathrm{C}$; já na estação chuvosa, as temperaturas mínimas variam entre 9 e $18^{\circ} \mathrm{C}$ e as máximas entre 33 e $39^{\circ} \mathrm{C}$ (BRASILEIRO et al. 2005). 

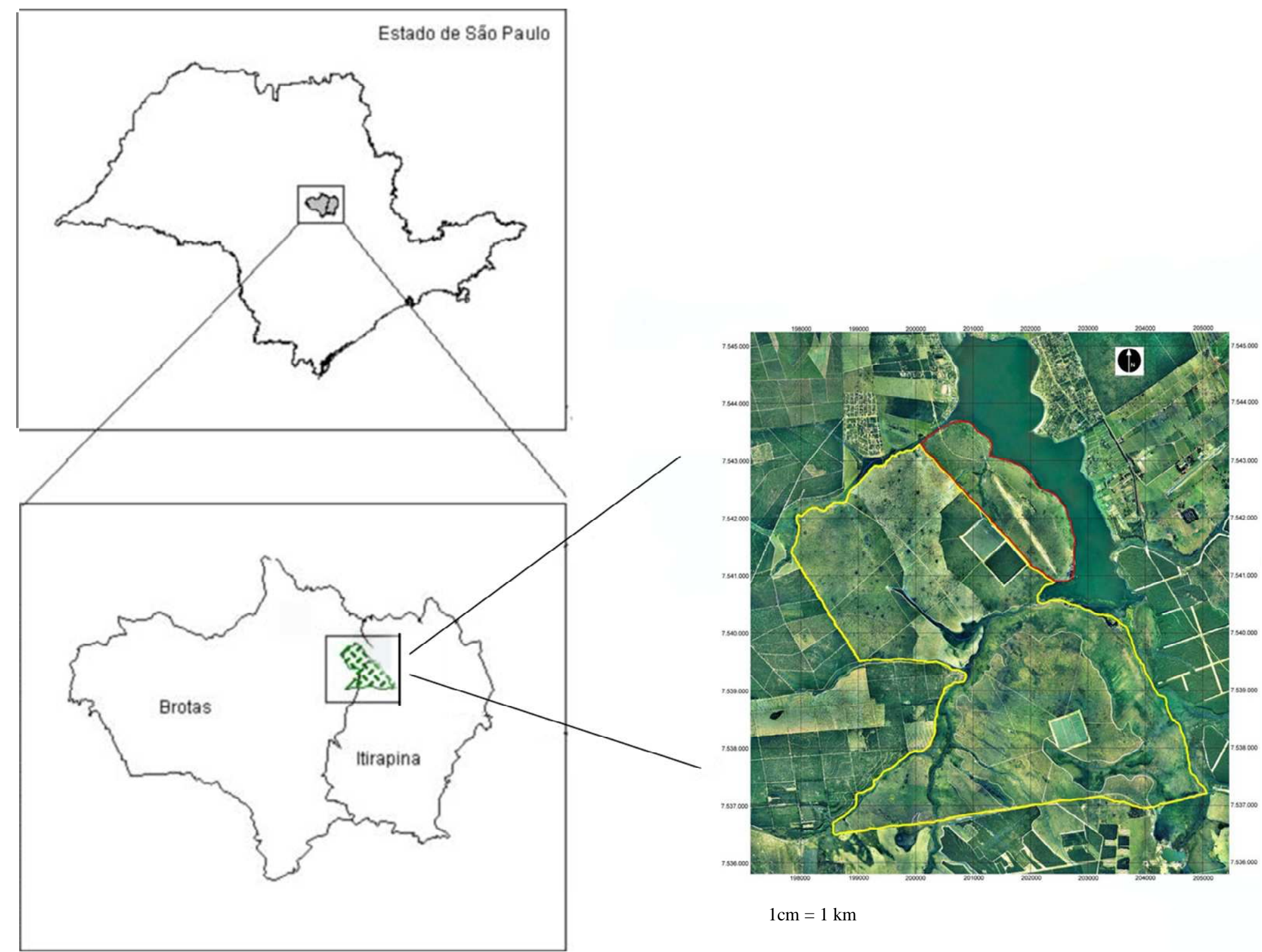

$1 \mathrm{~cm}=1 \mathrm{~km}$

Figura 3: Mapa da Estação Ecológica de Itirapina e sua localização no estado de São Paulo. — Limite da Estação Ecológica de Itirapina; — Limite da antiga área da USP (atualmente incorporada a Estação Ecológica). 
A Estação Ecológica de Itirapina (EEI) é a única área de Cerrado do Estado de São Paulo integrante das IBAs - áreas de importância para a conservação das aves. A sua inclusão ocorreu por abriga um número significativo de espécies globalmente ameaçadas e endêmicas (BENCKE et al., 2006).

Um estudo publicado recentemente registrou 231 espécies de aves para a EEI, sendo 38 delas $(16,4 \%)$ endêmicas ou ameaçadas, segundo a lista de espécies ameaçadas para o estado de São Paulo (MOTTA-JUNIOR et al., 2008). Mesmo com essa importância diversos fatores ameaçam a qualidade da EEI, entre estes estão: a invasão de plantas exóticas, principalmente de Brachiaria decumbens (capim braquiária) e Melinis minutiflora (capim gordura) capazes de invadir áreas nativas em locais arados ou de borda (WILLIS, 2004); a invasão por Pinus spp. encontrados na própria EEI e no seu entorno; a presença de caçadores ilegais e a invasão de animais como gado e cabras (MOTTA-JUNIOR et al.,2008). Os resultados dessas alterações são: a erosão do solo e a perda de habitat para a fauna (BENCKE et al., 2006).

O presente estudo foi realizado nas fitofisionomias abertas do Cerrado adotando-se a classificação sugerida por Coutinho (1978):

1) Campo limpo - campo com apenas formações campestres (Figura 4);

2) Campo sujo - vegetação campestre com arbustos bem espaçados e sem árvores (Figura 5);

3) Campo cerrado - apresenta uma vegetação arbustiva mais aberta e poucas árvores com menos de $5 \mathrm{~m}$ de altura e esparsas (Figura 6);

4) Cerrado sensu stricto - presença de árvores espaçadas podendo atingir alturas superiores a $5 \mathrm{~m}$ e arbustos e subarbustos mais próximos (Figura 7). 
Também foram amostradas as áreas alteradas que já se apresentam em recuperação com características de campo sujo (Figura 8).

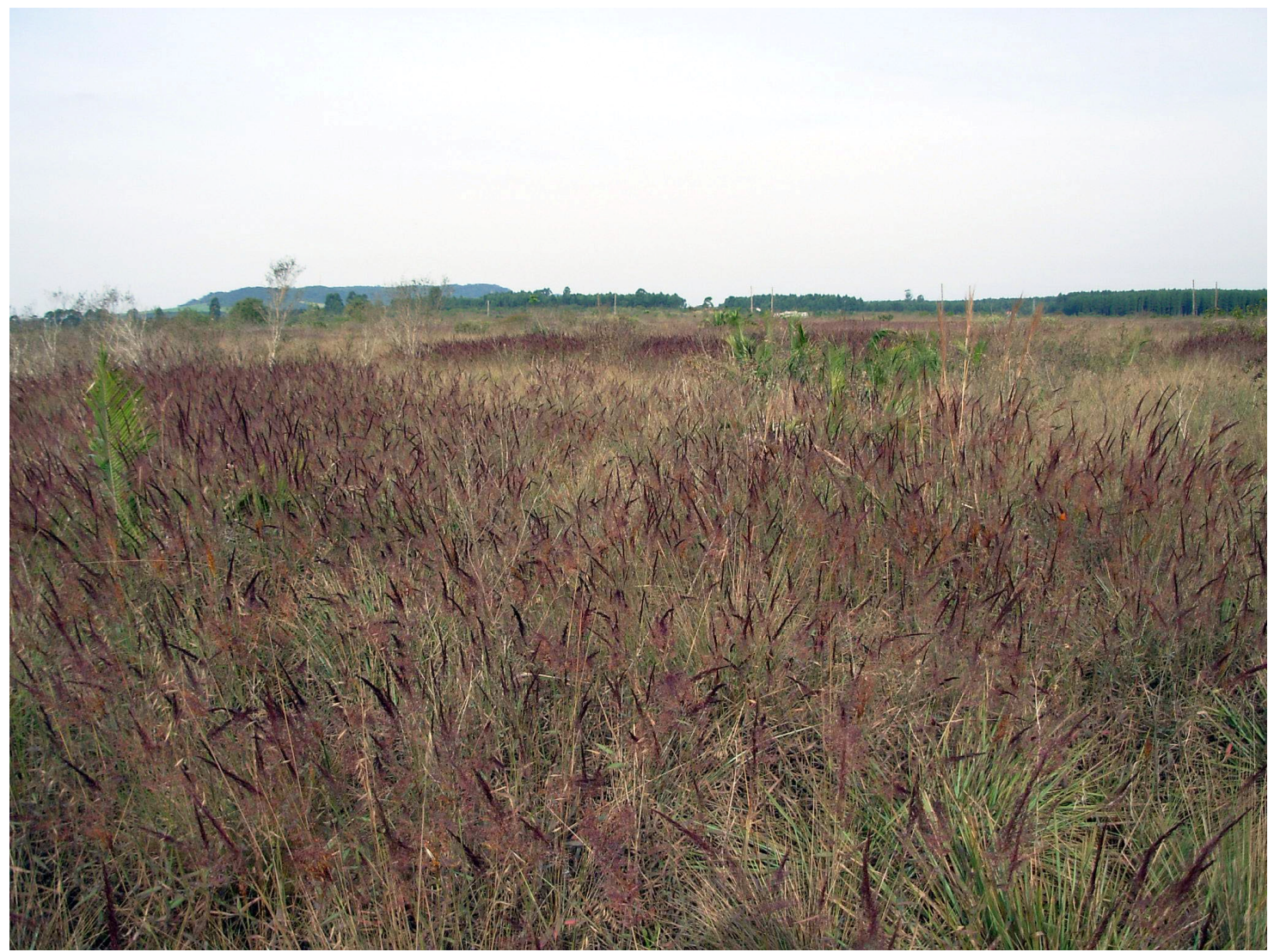

Figura 4: Campo limpo na Estação Ecológica de Itirapina, São Paulo. 


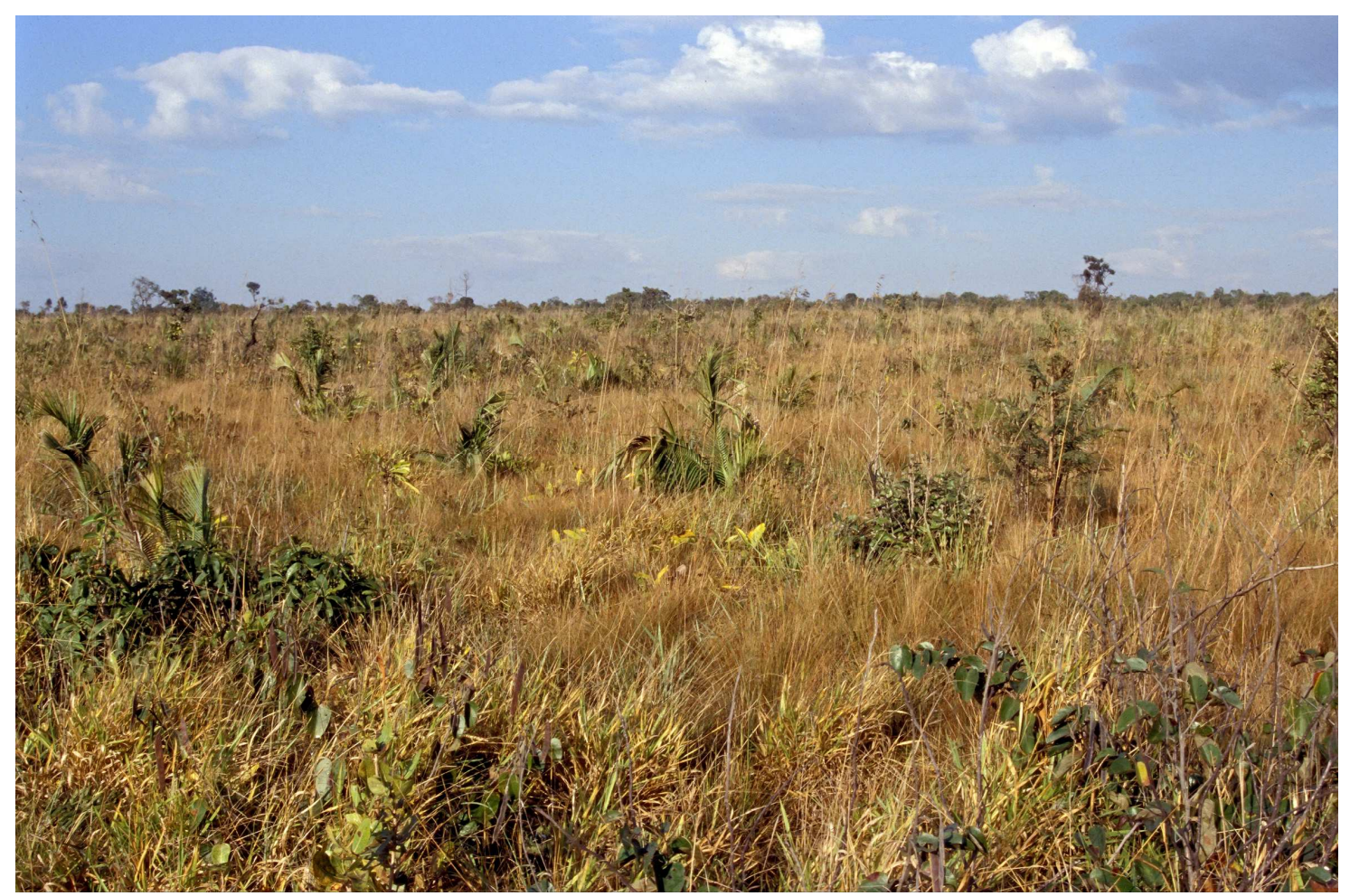

Figura 5: Campo Sujo na Estação Ecológica de Itirapina, São Paulo.

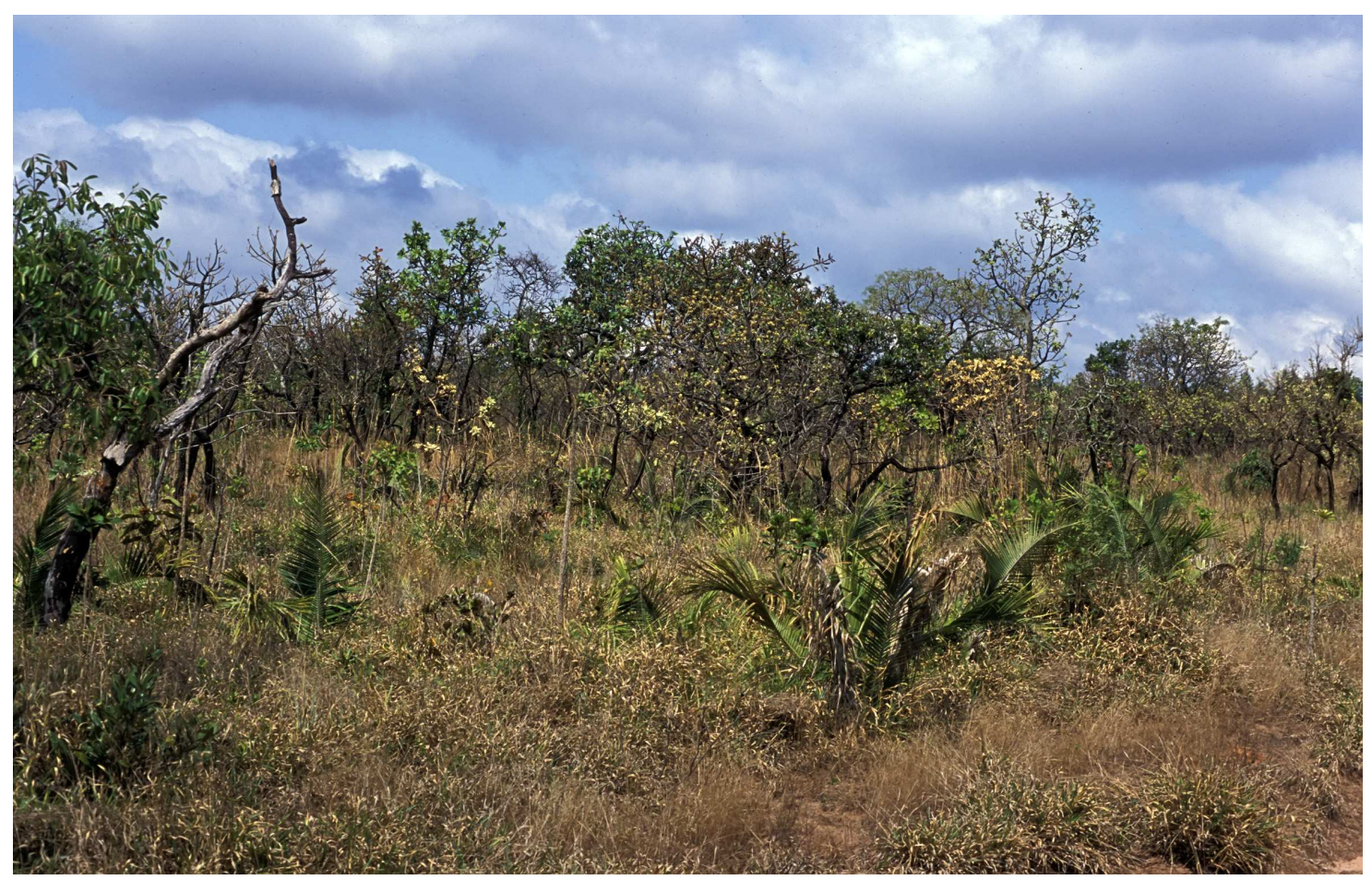

Figura 6: Campo cerrado na Estação Ecológica de Itirapina, São Paulo. 


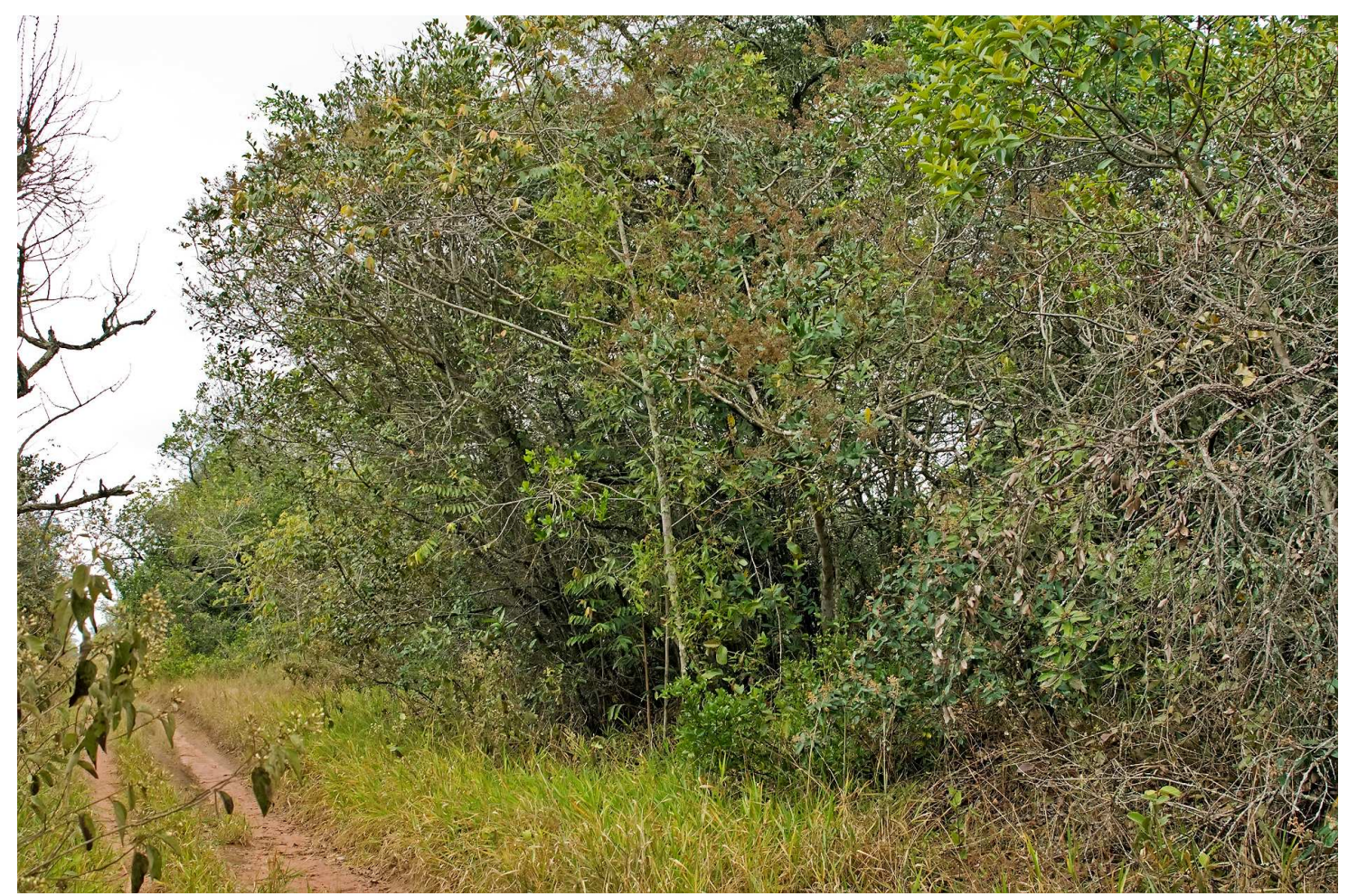

Figura 7: Cerrado sensu stricto na Estação Ecológica de Itirapina, São Paulo.



Figura 8: Área alterada em recuperação com características de campo sujo na Estação Ecológica de Itirapina São Paulo. Em primeiro plano base de troco de Pinus cortado. 


\subsection{Coleta de dados}

\subsubsection{Amostragem das aves}

O estudo foi realizado mensalmente no período reprodutivo, quando as aves estão mais ativas e conspícuas, entre setembro e dezembro de 2007 e em setembro de 2008. Para localizar as aves na EEI foi elaborado um desenho amostral sistemático. Krebs (1999) coloca a amostragem sistemática como efetiva e aplicável em condições de campo, desde que se evitem vieses de ciclos (tais como horários de amostragem), o que se procurou evitar.

Utilizando-se os aceiros e estradas de terra transitáveis da EEI foram demarcados sistematicamente 84 pontos de observação para a procura das aves com uma distância mínima de $300 \mathrm{~m}$ entre eles. Tal distância foi superior aos $200 \mathrm{~m}$ sugerido por Bibby et al. (2000) para minimizar ainda mais a chance de duplicação dos dados. Cada ponto de observação foi georreferenciado com o auxílio de um GPS (Garmin eTrex) e marcado com uma fita colorida para que ao longo dos cinco meses de estudo fosse possível retornar ao mesmo local. O período de observação/procura das aves em cada ponto foi de 10 min no qual o pesquisador ficou parado registrando os contatos visuais e auditivos. No caso de haver um bando da mesma espécie o registro foi considerado como um contato único.

Todos os pontos de observação foram visitados uma vez por mês e, ao longo dos meses em diferentes horários do dia (manhã/tarde). O período de amostragem ocorreu até 4 h após o amanhecer e no final da tarde, sempre após as 16:00 h, períodos estes em que as aves estão mais ativas. Em cada período de amostragem, o primeiro ponto e a direção do percurso para os próximos foram sorteados mantendo-se uma distância mínima de $600 \mathrm{~m}$ entre os pontos realizados para se minimizar/evitar o risco de duplicação dos dados. 
Condições climáticas desfavoráveis à observação de aves, como chuva e ventos fortes, foram evitadas.

A nomenclatura científica adotada foi a proposta pelo Comitê Brasileiro de Registros Ornitológicos (CBRO, 2008). Para responder as questões do presente trabalho sobre o uso e seleção de habitat e das características da vegetação que podem influenciar na presença das espécies, foram adotadas duas escalas diferentes, definidas segundo Garshelis (2000). Na primeira, a da paisagem, chamada aqui de seleção de macro-habitat, considerouse as diferentes fitofisionomias abertas do Cerrado. Na segunda escala que analisa manchas específicas dentro do habitat, chamada aqui de micro-habitat, quantificou-se os componentes específicos da vegetação no exato local utilizado pelas aves.

\subsubsection{Uso e seleção de macro-habitat}

Os 84 pontos de observação abrangeram as diferentes fitofisionomias do Cerrado incluindo campo limpo, campo sujo, campo cerrado e cerrado sensu stricto, sendo distribuídos em uma proporção próxima de sua disponibilidade na paisagem da EEI (Tabela 1). Os registros das aves foram feitos tanto por meio de contatos visuais com o auxílio de binóculo (Nikon 7,5 x 35), como por contatos auditivos quando era possível definir exatamente em qual das fitofisionomias a ave se encontrava.

Para definir os tipos a as porcentagens de cada habitat na área de estudo foi realizada a análise do índice de vegetação da diferença normalizada (IVDN), por meio de imagens de satélites do CBERS 2, fornecidas pelo Instituto de Pesquisas Espaciais (INPE). O IVDN foi calculado utilizando-se as faixas do infravermelho próximo e do vermelho (MESQUITA-JUNIOR， 1998; BITENCOURT \& MESQUITA-JUNIOR， 2005). A classificação dos tipos de fitofisionomias foi feita atribuindo-se valores para as diferentes 
classes com base nas observações de campo e considerando-se as assinaturas espectrais sugeridas em Mesquita-Junior (1998). Como resultado foi gerado um mapa da vegetação da EEI, no qual o campo limpo e o campo sujo foram agrupados em uma categoria denominada áreas campestres, pois a diferença entre eles é sutil, apenas a presença de poucos arbustos no campo sujo, o que não permitiu uma diferenciação segura (Figura 9). 


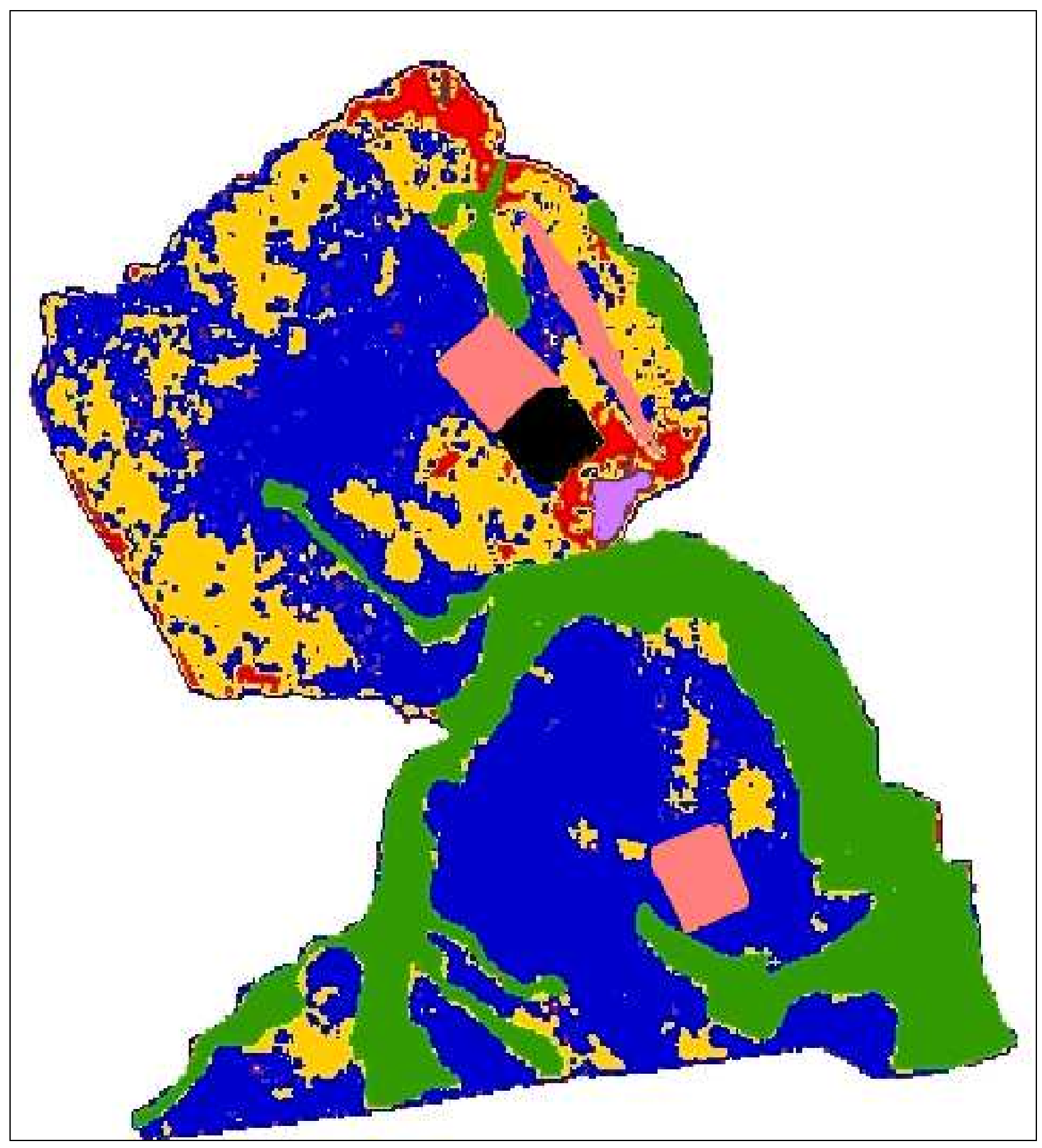

Figura 9: Mapa de classificação das diferentes fitofisionomias presentes na Estação Ecológica de Itirapina. A Áreas campestres (campo limpo e campo sujo); campo cerrado; cerrado sesu stricto;

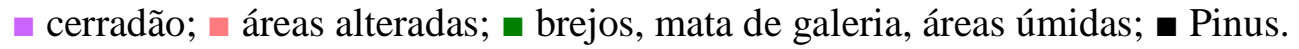


A análise de uso e seleção de habitat foi baseada na abordagem de uso e disponibilidade, a qual considera o número de observações de uma espécie em um determinado habitat em relação à disponibilidade do mesmo na paisagem (GARSHELIS, 2000). Para verificar a seleção ou rejeição de um habitat foram calculados intervalos de confiança simultâneos (NEU et al., 1974; BYERS \& STEINHORST, 1984). O intervalo de confiança utilizado foi o de Bailey por ser mais robusto para amostras pequenas e fornecer um erro menor em relação a outros intervalos (CANAVELLI, 2003; CHERRY, 1996).

Tabela 1: Tipo de habitat amostrado, tamanho da área de cada habitat, porcentagem dos mesmos, número de pontos amostrados das aves em cada habitat e suas respectivas porcentagens.

\begin{tabular}{lcccc}
\hline \multicolumn{1}{c}{ Habitats } & Área (ha) & $\begin{array}{c}\text { Porcentagens } \\
\text { dos habitats } \\
\text { disponíveis }\end{array}$ & $\begin{array}{c}\text { Número de } \\
\text { pontos } \\
\text { amostrados/mês }\end{array}$ & $\begin{array}{c}\text { Porcentagens } \\
\text { dos pontos } \\
\text { amostrados }\end{array}$ \\
\hline $\begin{array}{l}\text { Campo limpo, } \\
\text { campo sujo e áreas } \\
\text { alteradas* }\end{array}$ & 1277,76 & 64,84 & 52 & 61,91 \\
Campo cerrado & 571,44 & 29,00 & 28 & 33,33 \\
$\begin{array}{l}\text { Cerrado sensu } \\
\text { stricto }\end{array}$ & 121,36 & 6,16 & 4 & 4,76 \\
\hline Total & $\mathbf{1 9 7 0 , 5 6}$ & $\mathbf{1 0 0}$ & $\mathbf{8 4}$ & $\mathbf{1 0 0}$ \\
\hline
\end{tabular}

* Áreas alteradas correspondem às áreas em recuperação que atualmente apresentam características de campo sujo.

\subsubsection{Uso e seleção de micro-habitat}

Com relação ao micro-habitat, o registro das aves estudadas foi feito apenas pelos contatos visuais, pois era preciso saber o local exato onde a espécie estava para se quantificar os componentes da vegetação presentes no micro-habitat utilizado. 
O micro-habitat disponível foi caracterizado pelos 84 pontos de observação sendo estimados dentro de parcelas circulares com raio de $5 \mathrm{~m}$, onde o centro da circunferência foi o exato local do ponto de observação. Os dados sobre as características do micro-habitat utilizado por $S$. atricollis e por $C$. hirundinacea também foram estimados por parcelas circulares com raio de $5 \mathrm{~m}$, onde o centro da circunferência era o ponto exato onde se avistou um indivíduo (Figura 9). Pelo fato de alguns dos 84 pontos terem sido descritos tanto no ano de 2007 como no ano de 2008, foi sorteada apenas uma destas amostras e assim no estudo de micro-habitat disponível se obteve o total dos 84 pontos disponíveis.

Foram selecionadas 11 componentes da estrutura da vegetação que poderiam influenciar na presença das aves. Os componentes da vegetação estudados foram: porcentagem de cobertura de gramíneas nativas, porcentagem de cobertura de Brachiaria decumbens (braquiária), porcentagem de cobertura de Melinis minutiflora (capim gordura), porcentagem de solo exposto, porcentagem de cobertura de serapilheira, densidade de subarbustos e arbustos com até $1 \mathrm{~m}$ de altura, densidade de arbustos e arvoretas entre 1,1 e $2 \mathrm{~m}$ de altura, densidade de arbustos e árvores entre 2,1 e $4 \mathrm{~m}$ de altura, densidade de árvores acima de $4 \mathrm{~m}$ de altura, densidade da palmeira- Attalea geraensis (palmeira indaiá) e densidade da palmeira Syagrus petrea (palmeira coco de vassoura). As palmeiras foram consideradas separadas das outras herbáceas, pois poderiam servir como abrigo contra possíveis ataques de predadores, fonte de alimento ou aparecerem infestando áreas diminuído a disponibilidade de recursos utilizados pelas espécies. 


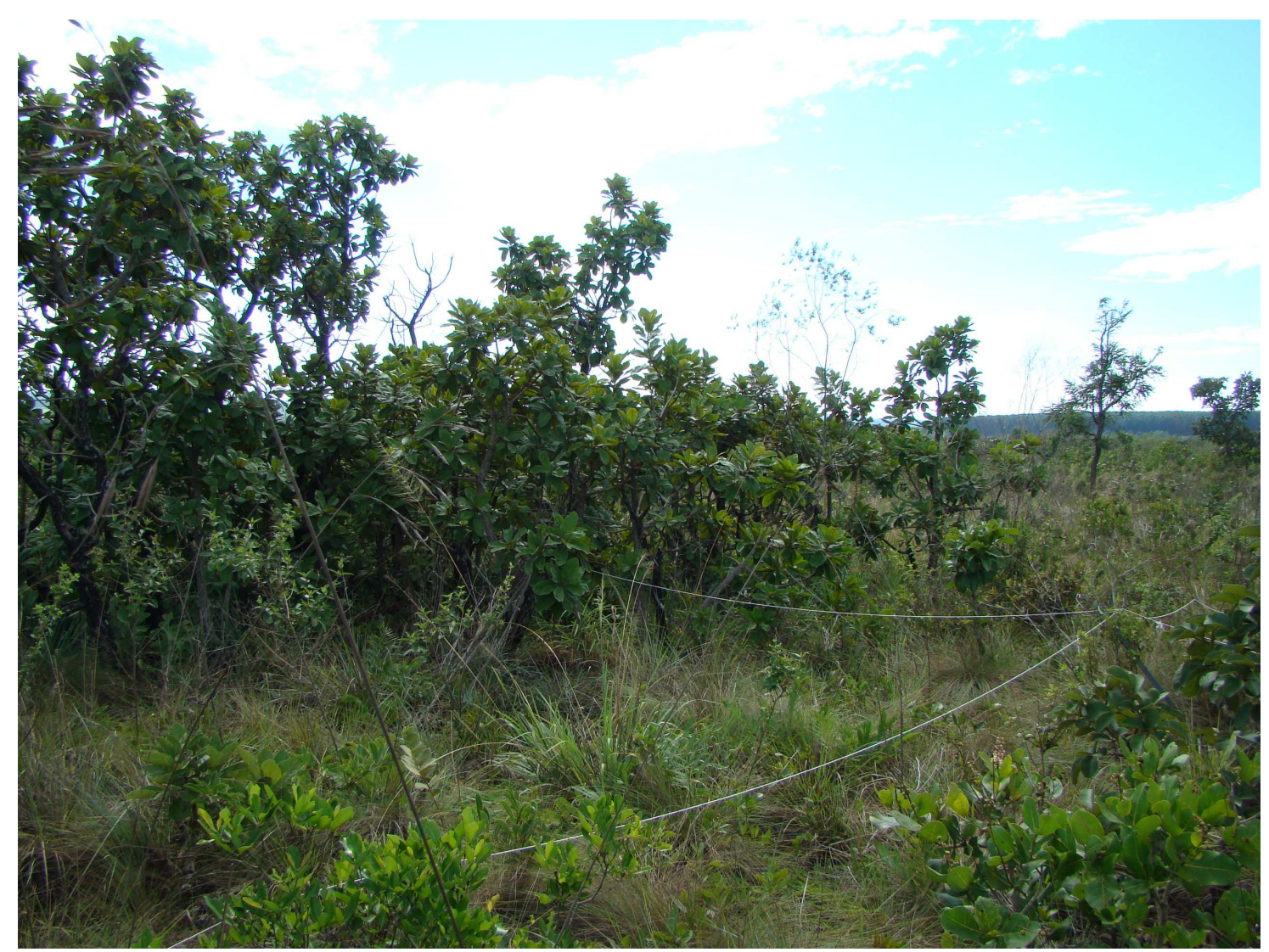

Figura 9: Barbante demarcando a parcela circular (raio de $5 \mathrm{~m}$ ) utilizada para a descrição dos componentes do micro-habitat.

Como as observações das aves ocorreram sempre no início da manhã e final da tarde foi possível identificar que o padrão de uso e seleção de micro-habitat estudado estava, na maioria das vezes, associado ao comportamento de forrageamento das espécies, pois é nesse horário que as aves estão mais ativas a procura de alimento.

A associação de $S$. atricollis ou $C$. hirundinacea com um ou alguns dos componentes da vegetação foi analisada por meio da seleção de modelos por regressão logística na qual a espécie de ave é a variável dependente e os componentes da vegetação são as variáveis independentes. Os modelos foram gerados somente com uma ou duas variáveis independentes para uma maior clareza na interpretação ecológica dos resultados. O modelo melhor ajustado foi selecionado pelo Critério de Informação de Akaike 
considerando-se a correção para amostras pequenas (AICc) proposta por HURVICH \& TSAI (1989). Os valores do AICc podem ser muito próximos e por isso não são suficientes para determinar os melhores modelos (WESTPHAL et al., 2003), portanto o peso do AIC (wi) que é a probabilidade de um modelo ser considerado o melhor entre todos os disponíveis, e a evidência, que compara quanto um modelo está próximo de outro (wi $\mathrm{i}_{\max } / \mathrm{wi}_{\bmod }$ ), também serviram para determinar o melhor modelo (BURNHAM \& ANDERSON 2002). Modelos com valor de evidência menor ou igual a dois devem ser considerados nas inferências (BURNHAM \& ANDERSON 2002). A análise foi realizada utilizando o pacote de modelos lineares generalizados (glm) no programa R 2.7.1 (2008 The R Foundation for Statistical Computing).

Um fator importante a ser considerado no ajuste da regressão é a multicolinearidade (FARRAR \& GLAUBER, 1967), ou seja, identificar fortes correlações entre variáveis independentes do modelo de regressão, e operar a modelagem sem considerá-las no mesmo conjunto para evitar confusões na interpretação dos padrões ecológicos analisados. Correlações superiores a $60 \%$ podem gerar dificuldade na interpretação e não é recomendado interpretar estas variáveis em uma mesma análise (ZAR 1999). Portanto, variáveis com tais correlações não foram analisadas em um mesmo modelo.

Para avaliar se não havia diferenças nos dados coletados em anos diferentes (ano de 2007 e 2008) e, assim, definir se estes poderiam ser agrupados como uma amostra única sem viés realizou-se o teste não paramétrico de Mann-Whitney (teste-U). Segundo SOKAL (1987) esse teste identifica se duas amostras de uma população possuem uma mesma distribuição. Para cada um dos 11 componentes estudados se comparou os dados coletados no micro-habitat em 2007 com os dados de 2008. Os resultados foram considerados 
estatisticamente significativos para os valores de $p<0,05$. Este procedimento foi realizado através do programa BioEstat 5.0 (AYRES et al. 2007).

\section{RESULTADOS}

\subsection{Uso e seleção de macro-habitat}

Foi obtido um total de 133 observações para S. atricollis distribuídas nos seguintes habitats, 83 nas áreas campestres, 46 no campo cerrado e 4 no cerrado sensu stricto. A espécie selecionou apenas áreas de campo cerrado e utilizou menos que o esperado áreas de cerrados sensu stricto. Com relação às fisionomias campestres, estas foram usadas na mesma proporção que o esperado (Tabela 2 e Figura 10).

Com relação à Cypsnagra hirundinacea, foram obtidas 137 observações sendo que 94 ocorreram nas áreas campestres, 42 no campo cerrado e 1 no cerrado sensu stricto. A espécie evitou as áreas de cerrado sensu stricto e utilizou na mesma proporção que o esperado as fisionomias campestres e o campo cerrado (Tabela 3 e Figura 10).

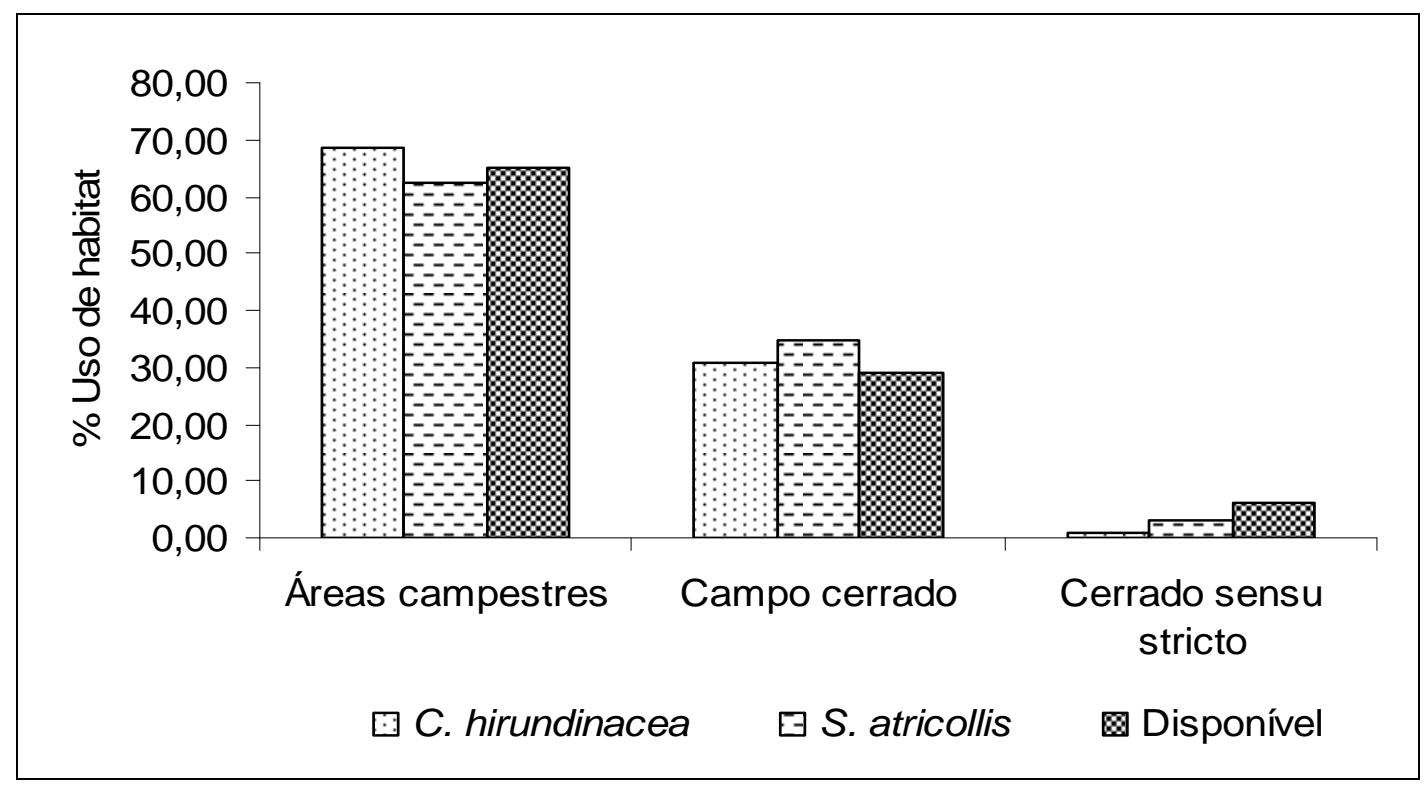

Figura 10: Porcentagem de habitat utilizado por Saltator atricollis $(\mathrm{N}=133)$, por Cypsnagra hirundinacea $(\mathrm{N}=137)$ e porcentagem de habitat disponível. 
Tabela 2: Análise de seletividade de habitat pelo intervalo de confiança simultâneo de Bailey para Saltator atricollis nas diferentes fitofisionomias abertas da EEI.

\begin{tabular}{c|ccccc}
\hline Habitat & $\begin{array}{c}\text { Tamanho } \\
\text { da área } \\
\text { (ha) }\end{array}$ & $\begin{array}{c}\text { Proporção } \\
\text { de uso } \\
\text { observado } \\
\text { (pi) }\end{array}$ & $\begin{array}{c}\text { Proporção } \\
\text { de uso } \\
\text { esperado }\end{array}$ & $\begin{array}{c}\text { Intervalo de } \\
\text { Bailey }\end{array}$ & $\begin{array}{c}\text { Tendência } \\
\text { de uso }\end{array}$ \\
\hline CL/CS & 1277,76 & 0,624 & 0,648 & $0,573 \leq \mathrm{pi} \leq 0,667$ & $=$ \\
CC & 571,44 & 0,346 & 0,290 & $0,299 \leq \mathrm{pi} \leq 0,393$ & + \\
CSS & 121,36 & 0,030 & 0,062 & $0,018 \leq \mathrm{pi} \leq 0,058$ & - \\
\hline
\end{tabular}

CL/ CS: áreas campestres (campo limpo e campo sujo); CC: campo cerrado; CSS: cerrado sensu stricto; pi: proporção real de uso em cada fitofisionomia observada; (=): utilizado conforme esperado; (+): utilizado mais que o esperado; (-): utilizado menos que o esperado.

Tabela 3: Análise de seletividade de habitat pelo intervalo de confiança simultâneo de Bailey para Cypsnagra hirundinacea nas diferentes fitofisionomias abertas da EEI.

\begin{tabular}{c|ccccc}
\hline Habitat & $\begin{array}{c}\text { Tamanho } \\
\text { da área } \\
\text { (ha) }\end{array}$ & $\begin{array}{c}\text { Proporção } \\
\text { de uso } \\
\text { observado } \\
\text { (pi) }\end{array}$ & $\begin{array}{c}\text { Proporção } \\
\text { de uso } \\
\text { esperado }\end{array}$ & $\begin{array}{c}\text { Intervalo de } \\
\text { Bailey }\end{array}$ & $\begin{array}{c}\text { Tendência } \\
\text { de uso }\end{array}$ \\
\hline CL/CS & 1277,76 & 0,686 & 0,648 & $0,638 \leq \mathrm{pi} \leq 0,726$ & $=$ \\
CC & 571,44 & 0,307 & 0,290 & $0,262 \leq \mathrm{pi} \leq 0,353$ & $=$ \\
$\mathrm{CSS}$ & 121,36 & 0,007 & 0,062 & $0,004 \leq \mathrm{pi} \leq 0,028$ & - \\
\hline
\end{tabular}

CL/ CS: fisionomias campestres (campo limpo e campo sujo); CC: campo cerrado; CSS: cerrado sensu stricto; pi: proporção real de uso em cada fitofisionomia observada; (=): utilizado conforme esperado; (-): utilizado menos que o esperado.

\subsection{Uso e seleção de micro-habitat}

Foram obtidas 32 visualizações de Saltator atricollis e 28 visualizações de Cypsnagra hirundinacea ao longo dos cinco meses de estudo as quais serviram para descrever o micro-habitat utilizado pelas espécies.

Foram coletados 75 pontos do micro-habitat disponível no ano de 2007 e 34 pontos no ano de 2008. O teste de Mann-Whitney não apresentou valores significativos com 
relação a cada um dos componentes da vegetação analisados entre os diferentes anos de estudo ( $p>0,05$ ) permitindo que os dados fossem agrupados e analisados como uma amostra única (anexo1).

O melhor modelo selecionado pelo AICc para explicar a presença de S. atricollis incluiu micro-habitats compostos por uma maior densidade de árvores com mais de $4 \mathrm{~m}$ de altura e um menor número de arbustos até $1 \mathrm{~m}$ de altura. Além desse modelo, outros três também foram significativos para a presença da espécie e todos eles incluíram o maior número de árvores (> $4 \mathrm{~m}$ ) o que mostra a importância dessa variável na presença da espécie. S. atricollis também está relacionada positivamente com o maior número de árvores com 2 a 4 m de altura e o menor número de Syagrus petrea (Tabela 4).

Tabela 4: Resultados significativos da seleção de modelos (AIC) para a explicação da presença de Saltator atricollis em relação as variáveis independentes. Os modelos estão ordenados do maior para o menor wAIC. Observa-se também as variáveis incluídas em cada modelo, o AIC corrigido (AICc) e o valor de evidência (valores $\leq 2$ ).

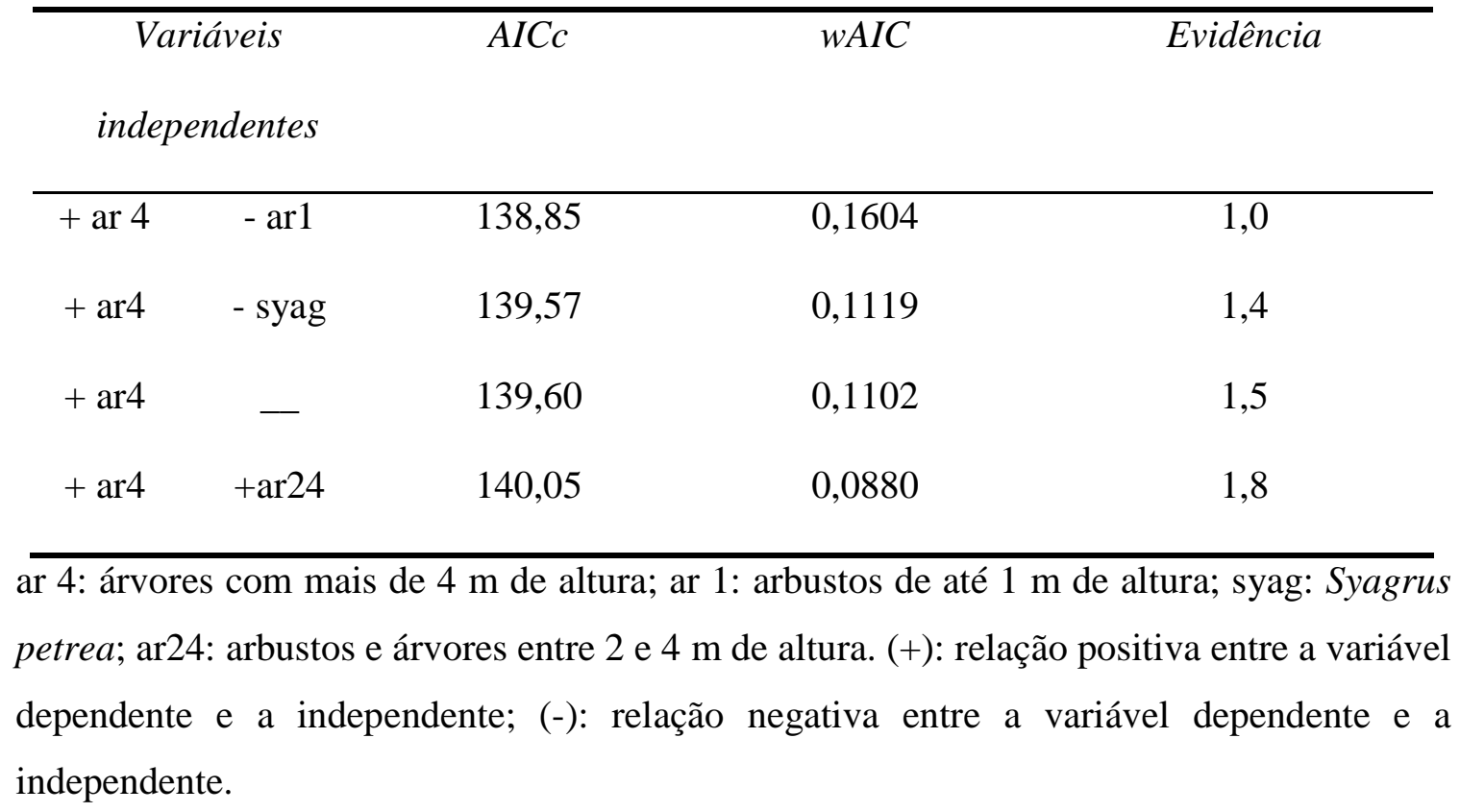


O modelo mais relevante para a ocorrência de $C$. hirundinacea foi representado pela menor densidade de Attalea geraensis e cobertura de solo exposto (Tabela 5). Outros modelos também foram significativos para explicar a ocorrência da espécie os quais indicaram que quanto maior a densidade de Attalea geraensis menor a chance de ocorrer Cypsnagra hirundinacea. Além disso, a espécie em questão ocorreu mais em microhabitats com maior densidade de árvores entre 2 e $4 \mathrm{~m}$ de altura, de Syagrus petrea, arbustos e arvoretas de 1 a $2 \mathrm{~m}$ de altura, árvores maiores que $4 \mathrm{~m}$ de altura e braquiária.

Tabela 5: Resultados significativos da seleção de modelos (AIC) para a explicação da presença de Cypsnagra hirundinacea em relação as variáveis independentes. Os modelos estão ordenados do maior para o menor wAIC. Observa-se também as variáveis incluídas em cada modelo, o AIC corrigido (AICc) e o valor de evidência (valores $\leq 2$ ).

\begin{tabular}{ccccc}
\hline \multicolumn{2}{c}{ Variáveis } & AICc & wAIC & Evidência \\
\multicolumn{2}{c}{ independentes } & & & \\
\hline - atta & - sexp & 124,26 & 0,0928 & 1,0 \\
- atta & + ar24 & 124,33 & 0,0896 & 1,0 \\
- atta & - & 124,36 & 0,0884 & 1,1 \\
- atta & + ar12 & 124,76 & 0,0723 & 1,3 \\
- atta & + ar 4 & 124,80 & 0,0708 & 1,3 \\
- atta & + bra & 125,43 & 0,0517 & 1,8 \\
\hline
\end{tabular}

Att: Attalea geraensis; sexp: solo exposto; ar24: arbustos e árvores entre 2 e $4 \mathrm{~m}$ de altura; ar12: arbustos e arvoretas ente 1 e $2 \mathrm{~m}$ de altura; ar 4: árvores com mais de $4 \mathrm{~m}$ de altura; bra: braquiária; (+): relação positiva entre a variável dependente e a independente; (-): relação negativa entre a variável dependente e a independente. 


\section{DISCUSSÃO}

\subsection{Uso e seleção de macro-habitat}

Saltator atricollis é descrito habitando as paisagens abertas do Cerrado (SICK, 1997; BAGNO \& MARINHO-FILHO, 2001). Contudo, no presente estudo, o campo cerrado, formado por uma vegetação arbustiva e árvores esparsas com até $5 \mathrm{~m}$ de altura, foi a única fisionomia selecionada pela espécie. Kanegae (2009) avaliou a densidade de $S$. atricollis na mesma localidade e também constatou este padrão. Outros estudos também encontraram a espécie em áreas de campo cerrado, porém não abordaram se havia seleção entre as diferentes fisionomias (MOTTA-JUNIOR \& VASCONCELLOS, 1996; DIAS, 2000; MOTTA-JUNIOR et al., 2008). Na Estação Ecológica de Águas Emendadas em Brasília, DF, em um estudo sobre tamanho de território de S. atricollis Berg \& Marini (2007a) localizaram quatro bandos de S. atricollis sendo que três deles estabeleceram território em área exclusiva de campo cerrado, o que também corrobora a preferência dessa espécie pela fisionomia de campo cerrado, conforme encontrado no presente estudo.

A escolha do macro-habitat pode estar diretamente relacionada com a escolha do micro-habitat, ou seja, o micro-habitat selecionado ocorre sempre dentro de um mesmo tipo de macro-habitat (GARSHELIS, 2000). Saltator atricollis deve selecionar o campo cerrado por encontrar nesta fisionomia o melhor conjunto de características favoráveis (um melhor micro-habitat) para sua sobrevivência e alimentação.

Saltator atricollis utilizou na mesma proporção que o disponível as fisionomias campestres. Como o estudo foi realizado no início da manhã e final da tarde, normalmente as observações foram de indivíduos sentinelas e animais forrageando. S. atricollis utiliza principalmente o estrato herbáceo (TUBELIS \& CAVALCANTI, 2000) forrageado no solo 
ou próximo a este (RAGUSA-NETTO, 2001; WILLIS \& ONIKI, 2003), característica esta disponível nas fisionomias campestres. Portanto a presença dessa espécie nas fisionomias campestres deve estar associada principalmente ao comportamento de forrageamento.

Saltator atricollis utilizou menos do que o disponível as áreas de cerrado sensu stricto. Esta fisionomia apresenta mais da metade do terreno sombreado por árvores e não possui gramíneas recobrindo o terreno (DURIGAN et al., 2004) o que possivelmente impede que a espécie utilize essa fisionomia como área reprodutiva. Berg \& Marini (2007b) estudaram aspectos da biologia reprodutiva de S. atricollis na Estação Ecológica de Águas Emendadas em Brasília, DF. Os autores encontraram seis ninhos da espécie, todos em áreas abertas construídos em moitas de gramíneas.

Cypsnagra hirundinacea é comumente observada em áreas do cerrado com poucas árvores e arbustos dispersos (RIDGELY \& TUDOR, 1989; SICK, 1997, TUBELIS \& CAVALCANTI, 2000). No presente estudo a espécie utilizou na mesma proporção que o disponível as fisionomias do campo cerrado e campestre. Kanegae (2009) estudou a densidade de $C$. hirundinacea na mesma área do presente trabalho e observou que a espécie apresenta densidade similar no campo cerrado e nas áreas campestres indicando não haver seleção destas fisionomias o que está de acordo com o observado no presente estudo.

No caso de $C$. hirundinacea, a escolha do macro-habitat também está relacionada à escolha do micro-habitat. Esta ave utiliza árvores e arbustos para forragear e raramente desce ao solo (RIDGELY \& TUDOR, 1989; RAGUSA-NETTO, 1997). Como já mencionado anteriormente, a maior parte das observações do presente estudo foram de animais exercendo a função de sentinela e forrageando. Tanto no campo sujo como no 
campo cerrado podemos encontrar arbustos os quais são utilizados no forrageamento da espécie e por isso ambas fisionomias podem ser utilizadas pela espécie.

Cypsnagra hirundinacea também utilizou menos do que o disponível as áreas de cerrado sensu stricto, o que pode estar relacionado à presença de uma maior cobertura arbórea a qual pode diminuir a detectabilidade de predadores pela espécie, que algumas vezes atua como líder e sentinela dos grupos heteroespecíficos no Cerraado (RAGUSANETTO, 2000; 2002).

A semelhança encontrada no uso de macro-habitat entre Saltator atricollis e Cypsnagra hirundinacea (ambas espécies utilizaram na mesma proporção que o esperado as fisionomias campestres e utilizaram menos que o disponível o cerrado sensu stricto) pode estar relacionada ao fato dessas espécies participarem juntas de bandos heteroespecíficos. Nestes bandos, normalmente há um individuo exercendo a função de sentinela enquanto o restante do grupo forrageia o que diminui o risco de predação do bando (RAGUSA-NETTO, 2000; 2002). Assim, mesmo utilizando estratos diferentes, $S$. atricollis utiliza mais o estrato herbáceo e $C$. hirundinacea os arbustos e árvores, o macrohabitat utilizado por essas espécies por muitas vezes é o mesmo.

\subsection{Uso e seleção de micro-habitat}

A relação positiva tanto de Saltator atricollis como de Cypsnagra hirundinacea com áreas onde há mais árvores maiores que $2 \mathrm{~m}$ de altura observada no estudo de microhabitat pode estar relacionada ao comportamento de sentinela, já que a maioria dos indivíduos observados estava exercendo essa função. Nesse comportamento, um indivíduo do bando (o sentinela) fica empoleirado em árvores ou arbustos vigiando contra possíveis ataques de predadores enquanto o restante do grupo forrageia. Caso o sentinela veja um 
predador, ele emite um som de alerta e o grupo se esconde na vegetação, o que diminui o sucesso de ataques de predadores (RAGUSA-NETTO, 2000; 2002). Portanto, as árvores presentes no micro-habitat podem ser utilizadas como poleiros pelos sentinelas dos bandos. Os sentinelas estão presentes tanto em bandos mono-específicos como em bandos heteroespecíficos os quais normalmente são liderados por S. atricollis (RAGUSA-NETTO, 2002, obs. pess.).

Além disso, $C$. hirundinacea pode selecionar esses micro-habitats devido à escolha de sítios para a reprodução. Os ninhos são construídos em árvores a uma altura média de 3,7 $\pm 0,3$ m e o casal habitualmente vocaliza próximo ao ninho (SANTOS, 2008) o que também pode explicar esta seleção. A repetição deste estudo de micro-habitat no período não reprodutivo pode esclarecer se a preferência por esse tipo de vegetação está mais relacionada ao comportamento de sentinela ou ao comportamento reprodutivo. As árvores e arbustos também são utilizados por $C$. hirundinacea durante o forrageamento quando a ave procura insetos e frutos nas folhagens e cascas dessas árvores, descendo raramente ao solo (RAGUSA-NETTO, 1997).

Cypsnagra hirundinacea também utilizou áreas com menor densidade de Attalea geraensis, além de locais com menor densidade de solo exposto e com maior densidade de arbustos e arvoretas entre 1 e $2 \mathrm{~m}$ de altura. Attalea geraensis possui o caule subterrâneo ou curto, 5 a 6 folhas recurvadas que medem cerca de $1,4 \mathrm{~m}$ de comprimento, e pode atingir até $1 \mathrm{~m}$ de altura (LORENZI et al., 1996). Pode ser encontrada na vegetação aberta do Cerrado, ocorrendo com maior frequência no campo sujo do que no campo limpo (BUENO et al., 2004) e é considerada infestante de pastos pelos pecuaristas (LORENZI et al., 1996). Apresenta um padrão de distribuição aglomerado que pode ficar mais crítico em fragmentos 
pequenos, provavelmente devido à ausência de animais dispersores capazes de levar as sementes a grandes distâncias (ALMEIDA \& GALETTI, 2007). Na EEI, a ausência de Dazyprocta azarae (paca), um possível agente dispersor das sementes da palmeira (HÜLLE, 2006), pode ter causado a formação de um padrão mais aglomerado de $A$. geraensis. Áreas com maior densidade de A. geraensis e maior porcentagem de solo exposto, podem diminuir a disponibilidade de arbustos e árvores que são utilizados por $C$. hirundinacea para forragear e por isso a espécie deve evitar esses locais. A estrutura das folhas de uma palmeira também não permite seu uso como poleiro (KANEGAE, 2009). Já a maior densidade de arbustos e arvoretas entre 1 e $2 \mathrm{~m}$ de altura pode fornecer maior disponibilidade de sítios para o forrageamento.

O fato de Cypsnagra hirundinacea ter selecionado áreas com maior quantidade de Brachiaria decumbens (gramínea exótica) deve ser analisado com certa cautela. A braquiária é originária da África e foi introduzida como forrageira no Brasil, sendo utilizada até hoje com esse objetivo (LORENZI, 1991), pode atingir $1 \mathrm{~m}$ de altura (KISSMANN, 1997) e apresenta uma maior estratificação de altura em relação às gramíneas nativas (PIVELLO et al., 1999a). Atualmente, a braquiária está presente em praticamente todas as áreas abertas dos fragmentos de Cerrado sendo uma forte competidora capaz de diminuir e até mesmo excluir gramíneas nativas (PIVELLO et al., 1999a, b). O sucesso na invasão nas áreas de Cerrado se deve a alta capacidade competitiva, alta produção de sementes, crescimento rápido (KLINK, 1994), e, além disso, ao fato de suas sementes germinam durante um longo período após o revolvimento do solo o que dificulta o controle químico (LORENZI, 1991). A invasão por braquiária em fragmentos nativos se inicia pelas bordas e a partir desse ponto vai se espalhando por toda a área (PIVELLO et al. 1999b). 
Cypsnagra hirundinacea é considerada de alta sensibilidade a distúrbios antrópicos (STOTZ et al., 1996). Entretanto no presente estudo $C$. hirundinacea selecionou áreas com braquiária a qual representa um distúrbio para o meio ambiente. C. hirundinacea raramente utiliza o estrato herbáceo então, enquanto a presença da braquiária só atuar nesse estrato sem prejudicar os arbustos e árvores, pode ser que o distúrbio não seja relevante e assim a espécie estudada conseguiria utilizar as áreas com braquiária. Porém com o passar dos anos pode ser que ocorra uma alteração na estrutura da vegetação já que a braquiária vai cobrir o solo em diferentes estratos o que poderá impedir o desenvolvimento de arbustos e ai sim interferir na presença da Cypsnagra hirundinacea. Como na EEI a invasão está principalmente entre as bordas até $100 \mathrm{~m}$ adentro dos fragmentos pode ser que ainda não tenha ocorrido alterações na estrutura da vegetação e sim somente a substituição das gramíneas nativas pela braquiária e por isso a $C$. hirundinacea pode utilizar as áreas com maior concentração de braquiária.

Rotemberry, J.T. (com. pess) afirma que ao se estudar uma espécie em um curto período do tempo pode-se não identificar o efeito negativo de distúrbios antrópicos, como por exemplo, a presença de gramíneas invasoras no habitat. Já em estudo de longo prazo é possível se observar esse efeito na vegetação a qual terá o processo de sucessão ecológica alterado, e a partir desse momento poderíamos verificar uma alteração na comunidade de aves ou outros grupos dependentes da estrutura da vegetação. Portanto o que se observou na EEI quanto ao uso de áreas com grandes quantidades de braquiária por $C$. hirundinacea pode estar relacionado ao fato de se tratar de um estudo pontual e curto refletindo apenas um pequeno período de expansão da braquiária em todo o processo de sucessão ecológica 
da área. Para se confirmar essa hipótese, seria necessário monitorar a abundância da espécie e o grau de invasão da braquiária na EEI ao logo dos anos.

Outra questão para se considerar na relação entre braquiária e $C$. hirundinacea é que mesmo utilizando micro-habitats com maior quantidade de braquiária, a cobertura máxima dessa gramínea encontrada no micro-habitat dessa ave foi de 58\%. Portanto, como parcelas circulares com mais de $58 \%$ de braquiária foram raras na EEI (apenas 4 dentre as 84 amostradas) e não ocorreram para $C$. hirundinacea, não se pode afirmar que a espécie é capaz de utilizar habitats com grandes áreas tomadas por braquiária (mais que $60 \%$ de cobertura).

Quanto ao micro-habitat utilizado por Saltator atricollis, além de selecionar locais com mais árvores (> $2 \mathrm{~m}$ ), a espécie também selecionou áreas com menor densidade de arbustos $(<1 \mathrm{~m}$ de altura) e menor densidade de Syagrus petrea, o que pode estar relacionado ao comportamento de forrageamento desta espécie. Como já mencionado anteriormente, Saltator atricollis utiliza principalmente o estrato inferior ou o chão para forragear (RAGUSA-NETTO, 2001; WILLIS \& ONIKI, 2003.).

Syagrus petrea é uma palmeira rasteira com o caule muito curto ou subterrâneo, possui 5 a 8 folhas de 30 a $120 \mathrm{~cm}$ de comprimento (na EEI raramente ultrapassam $50 \mathrm{~cm}$ (obs. pess.)), é comum em áreas de cerrado aberto e é resistente às queimadas (LORENZI et al., 1996). Apesar de fazer parte do estrato herbáceo, as folhas dessa palmeira são compostas por 10 a 50 pinas estreitas, distribuídas regularmente ou agrupadas em planos levemente diferenciados (LORENZI et al., 1996). o que torna difícil a sua utilização por uma ave tanto como poleiro como abrigo (obs. pess.). A alta densidade de arbustos também 
pode dificultar o acesso ao estrato herbáceo e consequentemente diminuir a disponibilidade de sítios para o forrageamento da espécie.

Saltator atricollis não demonstrou relação com a presença de gramíneas exóticas, ou seja, usou tanto áreas preservadas, como áreas alteradas. Essa capacidade de utilizar habitats alterados também foi observada por Berg \& Marini (2007a, b) os quais estudaram a territorialidade e a biologia reprodutiva da espécie na Estação Ecológica de Águas Emendadas, DF e observaram um bando com território estabelecido em área fortemente alterada e encontraram ninhos em áreas alteradas. S. atricollis. Porém estas observações vão contra ao encontrado por Tubelis \& Cavalcanti (2000), que em um estudo na Estação Ecológica do Jardim Botânico de Brasília e na Fazenda Água Limpa da Universidade de Brasília, encontraram $S$. atricollis apenas em áreas de cerrado preservadas, ou seja, áreas sem a presença de gramíneas exóticas (braquiária e capim gordura) ou com baixa densidade destas gramíneas. Essa contradição entre os estudos mencionados sugere a capacidade de $S$. atricollis conseguir utilizar tanto cerrados preservados como cerrados com alguma alteração.

As espécies estudadas apresentaram semelhanças no uso do macro-habitat as quais ocuparam, principalmente, as fisionomias mais abertas do Cerrado, ou seja, as áreas campestres (compostas por campo limpo e campo sujo) e o campo cerrado. Estas fisionomias já foram predominantes no estado de São Paulo, porém atualmente são pouco freqüentes (DURIGAN et al., 2004) devido à supressão da vegetação causada pelos proprietários de terras (BITENCOURT, 2004) e, de uns anos para cá, devido à proteção contra o fogo o que provoca o adensamento da vegetação (DURIGAN et al., 2004). Portanto, a urgente conservação dos últimos remanescentes dessas fisionomias deve ser 
encarada como essencial para a manutenção das espécies de aves típicas de cerrado aberto, como é o caso de Saltator atricollis e Cypsnagra hirundinacea.

Outra semelhança entre as espécies diz respeito ao micro-habitat, nenhuma delas foi influenciada negativamente pela presença de gramíneas exóticas, porém na área de estudo não ocorreu altas concentrações de capins exóticos. Por essa razão sugere-se realizar estudos quantitativos comparando a densidade dessas aves em áreas preservadas e em áreas com média e intensa concentração de gramíneas exóticas considerando-se também o tempo de invasão dos fragmentos (invasões recentes e antigas). Dessa forma será possível afirmar com maior clareza se as grandes concentrações de gramíneas exóticas diminuem a densidade das espécies no habitat e se um longo tempo de invasão influencia na presença das espécies.

O entorno imediato da EEI (raio de $1 \mathrm{~km}$ ) é composto principalmente por monocultura (62\% da área) e por urbanização (3\% do total da área), o que contribui para a invasão por gramíneas exóticas e prejudica principalmente as formações savânicas (GRANZINOLLI, 2009). Portanto, uma política que proteja a zona de amortecimento da EEI e possa minimizar a entrada de gramíneas exóticas para que essas não se tornem dominantes por toda a EEI é de grande importância para a preservação das áreas de cerrado aberto (campo limpo, campo sujo e campo cerrado), o que indiretamente ajudaria na proteção das espécies de aves que utilizam estas áreas. Além disso, o manejo e o controle dessas gramíneas dentro da EEI também são importantes para evitar que elas continuem a invadir as áreas ainda preservadas. 


\section{REFERÊNCIAS BIBLIOGRÁFICAS}

ALMEIDA L. B. \& M. GALETTI. 2007. Dispersal and spatial distribution of Attalea geraensis (Arecaceae) in two remnants of Cerrado in Southeastern Brazil. Acta Oecologica 32: $180-187$.

AUSDEN, M. 2008. In: Sutherland W. J.; I. Newton \& R. E. Green (ED). Bird Ecology and Conservation. Oxford University Press. 386 p.

AYRES, M.; M. AYRES-JUNIOR; D. L. AYRES \& A. S. SANTOS. 2007. BioStat Aplicações estatísticas na áreas das ciências biológicas e médicas. Belém, Sociedade Civil Mamirauá/MCT-CNPq/Conservation International. 364 p.

BAGNO, M.A. \& J. MARINHO-FILHO. 2001. A avifauna do Distrito Federal: uso de ambientes abertos e florestais e ameaças, p. 495-528. In: F. Ribeiro; C.E.L. Fonseca \& J.C. Sousa-Silva (Eds.). Cerrado: caracterização e recuperação de matas de galeria. Planaltina, Embrapa. 899 p.

BENCKE, G. A., G. N. MAURICIO, P. F. DEVELEY \& J. M. GOERCK. 2006. Áreas Importantes para a Conservação das Aves no Brasil. Parte I - Estados do Domínio da Mata Atlântica. Editora SAVE Brasil. 494 p.

BERG, S.B. \& M. A. MARINI. 2007a. Território de Saltator atricollis (Cardinalidae) no Cerrado do Distrito Federal. Livro de resumos do XV Congresso Brasileiro de Ornitologia. Porto Alegre. p 264.

BERG, S.B. \& M. A. MARINI. 2007b. Aspectos da biologia reprodutiva de Saltator atricollis, Cardinalidae no cerrado, Distrito Federal. Livro de resumos do XV Congresso Brasileiro de Ornitologia. Porto Alegre. p 119-120.

BIBBY, C.J.; B.N. PHILLIPS \& A.J.E. SEDDON. 1985. Birds of restocked conifer plantations in Wales. Journal of Applied Ecology 22: 619-633.

BIBBY, C.J.; N. D BURGESS; D. A. HILL \& S. H. MUSTOE. 2000. Birds Census Techniques. Londres, Elsevier Academic. 302 p. 
BITENCOURT, M. D. \& H. N. MESQUITA JR, 2005. Análise ambiental espacializada da Gleba Pé-de-Gigante. In: V.R. Pivello \& E. M. Varanda. (Eds). O Cerrado Pé-deGigante: ecologia e conservação - Parque Estadual de Vassununga. São Paulo, Secretaria do Meio Ambiente. Impressa oficial. 312 p.

BITENCOURT, M. D. 2004. Diagnóstico cartográfico dos remanescentes de cerrado em São Paulo. p. 17-28. In: Bitencourt \& R.R. M.D., Mendonça (Orgs). Viabilidade de Conservação dos remanescentes de cerrado no Estado de São Paulo. Annablume/FAPESP, São Paulo, 169p.

BLOCK, W. M. \& L. A. BRENNAN, 1993. The habitat concept in ornithology: Theory and applications. Pages 35-91. In: Power (Ed.). Current Ornithology, vol. 11. D. M. Plenum Press, New York.

BORGHESIO, L. \& P. LAIOLO. 2004. Habitat use and feeding ecology of Kulal White-eye Zosterops kulalensis. Bird Conservation International 14: 11-24.

BRASILEIRO, C.A.; R.J. SAWAYA; M.C. KIEFER \& M. MARTINS. 2005. Anfíbios de um fragmento de Cerrado aberto do sudeste do Brasil Biota Neotropica. 5 (2). Disponível na world wide web em: http://www.biotaneotropica.org.br/v5n2/pt/abstract?article+BN00405022005 • ISSN 1676-0603 [04/09/2008].

BUENO, A. A.; M.J. LAPENTA; F. OLIVEIRA \& J.C. MOTTA-JUNIOR. Association of the "IUCN vulnerable "spiny rat Clyomys bishopi (Rodentia:Echimyidae) with palm trees and armadillo burrows in southeastern Brazil. Rev. biol. trop. [online]. dic. 2004, vol.52, no.4 [citado 09 Julio 2009], p.1009-1011. Disponível em: World Wide Web: <http://www.scielo.sa.cr/scielo.php?script=sci_arttext\&pid=S0034$77442004001200023 \& \operatorname{lng}=e s \& n r m=i s o>$. ISSN 0034-7744.

BURNHAM, K. P. \& D. R. ANDERSON, 2002. Model selection and multimodel inference:a pratical information-theoretic approach. Springer, $488 \mathrm{p}$.

CANAVELLI, S. B., M. J. BECHARD, B.WOODBRIDGE., M. N. KOCHERT, J. J. MACEDA \& M. E. ZACCAGNINI, 2003. Habitat use by Swainson's hawks on their austral wintering grounds in Argentina. Journal of Raptor Research 37: 125-134. 
CAUGHLEY, G. 1994. Directions in conservation biology. Journal of Animal Ecology 63: 215-244.

CAVALCANTI, R.B. 1999. Bird species richness and conservation in the Cerrado Region of Central Brazil. 244-249. In P.D. Vickery \& J. R. Herkert (Eds). Studies in Avian Biology 19 Kansas, 308 p.

CBRO 2008. Lista das aves do Brasil do Comitê Brasileiro de Registros Ornitológicos. http://www.cbro.org.br/CBRO/listabr.htm (último acesso em 06/02/2008).

CHERRY, S. 1996. A comparison of confidence interval methods for habitat use availability studies. Journal of Wildlife Management 60: 653-658

CONWAY C. J. \& C. SULZMAN. 2007. Status and habitat use of the california black rail in the Southwestern USA. Wetlands 27: 987-998.

COUTINHO, L.M. 1978. O conceito de cerrado. Revista Brasileira de Botânica, 1: 17-23.

DEVELEY, P. F.; CAVANA, D.D. \& PIVELLO, V.G. 2005. Caracterização de Grupos Biológicos do Cerrado Pé-de-Gigante - Aves, p. 121-134. In: V.R. Pivello \& E. M. Varanda. (Es). O Cerrado Pé-de-Gigante: ecologia e conservação - Parque Estadual de Vassununga. São Paulo, Secretaria do Meio Ambiente. Impressa oficial. 312 p.

DIAS, M. M. 2000. Avifauna da Estação Ecológica de Jataí e Experimental de Luiz Antônio, São Paulo, Brasil. 285-301. In: J. E. Santos \& Pires J. S. R. (Eds.). Estação Ecológica de Jataí. São Carlos, Rima. 346p.

DURIGAN, G.; G.A.D.C. FRANCO, \& M.F.SIQUEIRA 2004. A vegetação dos remanescentes de cerrado no estado de São Paulo. p. 29-56. In: Bitencourt \& R.R. M.D., Mendonça (Orgs). Viabilidade de Conservação dos remanescentes de cerrado no Estado de São Paulo. Annablume/FAPESP, São Paulo, 169p.

DYKSTRA C. R.; J. L. HAYS; F. B. DANIEL \& M. M. SIMON. 2001. Home range and habitat use of suburban red-shouldered hawks in Southwestern Ohio. Wilson Bull. 113: 308-316.

FARRAR, D. E. \& R.R. GLAUBER. 1967. Multicollinearity in regression analysis: the problem revisited. Rev. Econ. and Statist. 49: 92-107 
FÁVARO, F.L. \& L. ANJOS. 2005. Microhabitat de Habia rubica (Vieillot) e Trichothraupis melanops (Vieillot) (Aves, Emberizidae, Thraupinae), em uma floresta atlântica do sul do Brasil. Revista Brasileira de Zoologia 22 (1): 213-217.

GARSHELIS, D. L. 2000. Delusions in habitat evaluation: measuring use, selection, and importance, p. 111-164. In: L, Boitani., T. K. Fuller (Eds.). Research techniques in animal ecology. Columbia University Press. 442 p.

GRANZINOLLI, M.A.M. 2009 Levantamento, área de vida, uso e seleção de habitats de Falconiformes na região central do Estado de São Paulo. Dissertação de Doutorado, Instituto de Biociências, Universidade de São Paulo, São Paulo. 224p.

HÜLLE, N. L. 2006. Mamíferos de médio e grande porte num remanescente de Cerrado no sudeste do Brasil (Itirapina, SP). Dissertação de Mestrado, Instituto de Biociências, Universidade de São Paulo, São Paulo. 78p.

HUTTO, R. L. 1985. Habitat selection by nonbreeding, migratory land birds. Pages 455476 In: M. L. Cody (Ed.). Habitat Selection in Birds. Academic Press. 558 p.

JONES, J. 2001.Habitat selection studies in avian ecology: A critical review. The Auk 118:557-562.

KANEGAE, M.F. 2009. Tamanho populacional, seleção de habitat e área de vida de algumas aves endêmicas e ameaçadas na Estação Ecológica de Itirapina, São Paulo. Dissertação de Doutorado, Instituto de Biociências, Universidade de São Paulo, São Paulo. 111p.

KISSMANN, K. G. 1997. Plantas infestantes e nocivas. São Bernardo do Campo, Basf. $608 \mathrm{p}$.

KLINK, C. A. 1996. Germination and seedling establishment of two native and one invading African species in the Brazilian cerrado. Journal of Tropical Ecology 12: 139-147

KLINK, C. A. \& R. B. MACHADO, 2005. A Conservação do Cerrado Brasileiro. Megadiversidade 1(1): 147-155 
KRAUSMAN, P.R. 1999. Some Basic Principles of Habitat Use. In: Launchbaugh, K.L.; K.D. Sanders \& J.C. Mosley (Ed) Grazing Behavior of Livestock and Wildlife. Idaho Forest. Wildlife \& Range Exp. Univ. of Idaho, Moscow.

KREBS, C.J. 1998. Ecological Methodology. Califonia, Benjamin Cummings, 620p.

LOPES, L. E. \& M. Â. MARINI, 2006. Home range and habitat use by Suiriri affinis and Suiriri islerorum (Aves: Tyrannidae) in the central Brazilian Cerrado. Studies on Neotropical Fauna and Environment 41(2): 87-92

LOPES, E. V.; G. H. VOLPATO; L. B. MENDONÇA; F. L. FÁVARO \& L. ANJOS. 2006. Abundância, microhabitat e repartição ecológica de papa-formigas (Passeriforme Thamnophilidae) na bacia hidrográfica do Rio Tibaji, Paraná, Brasil. Revista Brasileira de Zoologia 23(2): 395-403.

LORENZI, H. 1991. Plantas daninhas do Brasil: terrestres, aquáticas, parasitas, tóxicas e medicinais. Ed. Plantarium. Nova Odessa, São Paulo. 2a Ed.

LORENZI, H.; H. M.SOUZA; J. T MEDEIROS-COSTA; L. S. C.CERQUEIRA; N. VON BEHR, 1996. Palmeiras no Brasil: nativas e exóticas. Ed. Plantarium, Nova Odessa, São Paulo. 40 p.

MACHADO, R. B.; M. B. RAMOS NETO; P PEREIRA; E.CALDAS; D.GONÇALVES; N.SANTOS; K.TABOR; M. STEININGER. 2004. Estimativas de perda da área do Cerrado brasileiro. Conservation International do Brasil.

MANTOVANI, W. 1985. Análise florística e fitossociológica do estrato herbáceosubarbustivo do cerrado na reserva biológica de Mogi-Guaçú e em litirapina, SP. Tese de doutorado. Campinas: Instituto de Biologia da Universidade Estadual de Campinas, SP. 203 p.

MARINI, M Â \& F. I. GARCIA. 2005. Conservação de aves no Brasil. Megadiversidade 1 (1): 95-102.

MARSDEN, S.J.; M. WHIFFIN; L. SANDGROUVE; P. GUIMARÃES JR. 2000. Parrot populations and habitat use in and around two lowland Atlantic forest reserves, Brazil. Biological Conservation 96:209-217. 
MESQUITA JR, H. N. 1998. Análise temporal com sensor orbital de unidades fisionômicas de cerrado na Gleba Pé-de-Gligante (Parque Estadual de VassunungaSP). Dissertação de Mestrado. Departamento de Ecologia, Universidade de São Paulo, São Paulo.

MORRISON, M.L. 2002. Wildlife Restoration: techinique for habitat analysis and animal monitoring. Washington. Island Press. 209 p.

MOTTA-JUNIOR, J.C. \& L. A. DA S. VASCONCELLOS. 1996. Levantamento das aves do campus da Universidade Federal de São Carlos, estado de São Paulo, Brasil. Anais do VII Seminário Regional de Ecologia 7: 159-171.

MOTTA-JUNIOR, J.C.; M.A.M. GRANZINOLLI \& P.F. DEVELEY. 2008. Aves da Estação Ecológica de Itirapina, estado de São Paulo, Brasil. Biota Neotropica 8 (3). Disponível na world wide web em: http://www.biotaneotropica.org.br/v8n3/pt/abstract?article+bn00308032008 ISSN 16760603. [20/10/2008].

MYERS, N., R. A. MITTERMEIER; C. G. MITTERMEIER; G. A. B. FONSECA; J. KENT. 2000. Biodiversity hotspots for conservation priorities. Nature 403: 853-858.

PATTEN, M. A.; D.H. WolfE.; E. SHOChAT \& S. K. SHERROD. 2005. Effects of microhabitat and microclimate selection on adult survivorship of the lesser prairie-chicken. Journal of Wildlife Management 69: 1270-1278.

PIVELLO, V. R., SHIDA C. N. \& MEIRELLES, S. T. 1999a. Alien grasses in Brazilian savannas: threat to the biodiversity. Biodiversity and Conservation 8: 1281-1294.

PIVEllo, V. R., CARVAlHO, V. M. C., LOPES, P. F., PECCININI, A. A. \& ROSSO, S. 1999b. Abundance and distribution of native and alien grasses in a 'cerrado' (Brazilian savanna) Biological reserve. Biotropica 31: 71-82.

POLETTO, F.; L. ANJOS; E.V. LOPES; G.H.VOLPATO; P.P. SSERAFINI \& F.L. FAVARO. 2004. Caracterização do microhabitat e vulnerabilidade de cinco espécies de arapaçus (Aves: Dendrocolaptidae) em um fragmento florestal do norte do estado do Paraná, sul do Brasil. Ararajuba, 12 (2): 89-96. 
RAGUSA-NETTO, J. 1997. Sasonal variation in foraging behavior of Cypsnagra hirundinacea in campo-cerrado. Ararajuba 5 (1): 72-75.

RAGUSA-NETTO, J. 2000. Raptors and "campo-cerrado" bird mixed flock led by Cypsnagra hirundinacea (Emberizidae:Thraupinae). Revista Brasileira de Biologia 60 (3): 461-467.

RAGUSA-NETTO, J. 2001. Sentinel in Saltator atricollis (Passeriformes: Emberezidae). Revista Brasileira de Biologia 61: 317-322.

RAGUSA-NETTO, J. 2002. Vigilance towards raptors by nuclear species in bird mixed flocks in a Brazilian savannah. Studies on Neotropical Fauna and Environment 37 (3): 219-226.

RATTER, J.A., J.P.F. RIBEIRO \& S. T. BRIDGEWATER. 1997. The Brazilian Cerrado and threats to its biodiversity. Annals of Botany 80: 223-230.

RIDGELY, R. S. \& G.TUDOR. 1989. The Birds of South America - The Oscine Passerines. Vol 1. Oxford, Oxford University Press. 516p.

RODRIGUES, M.; L. A. CARRARAS; L. P. FARIA \& H. B. GOMES. 2005. Aves do Parque Nacional da Serra do Cipó: o Vale do Rio Cipó, Minas Gerais, Brasil. Revista Brasileira de Zoologia 22 (2): 328-338.

RODRIGUES, M.T. 2005. A biodiversidade dos cerrados: conhecimento atual e perspectivas, com uma hipótese sobre o papel das matas de galerias na troca faunística durante ciclos climáticos. p 236-246. In: Cerrado: Ecologia, Biodiversidade e Conservação. Scariot, A., Souza-Silva, J.C., Felfile, J.M. (Org). Ministério do Meio Ambiente.

ROTENBERRY, J.T. 1985. The role of habitat in avian community composition: physiognomy or floristics? Oecologia 67: 213-217

SÃO PAULO. 2008. Fauna ameaçada no Estado de São Paulo. Decreto Estadual nº. 3.494, Secretaria do Estado do Meio Ambiente. 
SECRETARIA DO MEIO AMBIENTE DE SÃO PAULO. 1997. Cerrado: Bases para a conservação e uso sustentável das áreas de cerrado do Estado de São Paulo. São Paulo: Secretaria do Meio Ambiente, SP, Brasil. 113p

SANTOS, L. R. 2008. Biologia reprodutiva e comportamento cooperativo em ninhos de Cypsnagra hirundinacea. Tese Mestrado. Brasília: Instituto de Ciências Biológicas. Universidade de Brasília, 88p.

SCHLOSSBERG, S. 2006; Abundance and habitat preferences of gray vireos (Vireo vicinior) on the Colorado Plateau. The Auk 123:33-44.

SICK, H. 1997. Ornitologia Brasileira. Rio de Janeiro, Nova Fronteira. 912p

SILVA, J. M. C. 1995. Birds of the Cerrado Region, South America. Steenstrupia 21:69-92.

SILVA, J. M. C. \& J. M. BATES. 2002. Biogeographic patterns and conservation in the South American Cerrado: A tropical savanna Hotspot. BioScience 52: 225-233.

SILVA, J.M.C. \& SANTOS, M.P.D. 2005. A importância relativa dos processos biogeográficos na formação da avifauna do Cerrado e de outros biomas brasileiros p.219233. In Scariot A., J.C. Sousa-Silva \& J.M. Felfili, (orgs). Cerrado: ecologia, biodiversidade e conservação. MMA, Brasília.

SOKAL, R. R. \& , F. J. ROHLF. 1987. Introduction to biostatistics. W. H. Freeman and Company, New York. 363p.

STOTZ, D.F.; T.A. FITZPATRICK; PARKER III, T.A.; \& D.K. MOSKOVITS. 1996. Neotropical Birds: Ecology and Conservation. Chicago, University of Chicago, 481p.

SUTHERLAND W. J.E R. E. GREEN. 2008. Habitat assessment. In: Sutherland W. J.; I. Newton, e R. E. Green (Ed). Bird Ecology and Conservation. Oxford University Press. United States. 386pp.

TELINO-JÚNIOR, W.R.; R.M. LYRA-NEVES; S.M. AZEVEDO-JÚNIOR \& M.E.L. LARRAZÁBAL. 2008. First occurrence of the Saltator atricollis Vieillot, 1817 (Aves, Cardinalidae) in the state of Pernambuco, Brazil. Ornithologia - Revista do Centro Nacional de Pesquisa para a Conservação das Aves Silvestres. 3:1-66. 
TUBELIS D. P. \& R.B. CALVALCANTI. 2000. A comparison of bird communities in natural and disturbed non-wetland open habitats in the Cerrado's central region, Brazil. Bird Conservation International 10:331-350.

TUBELIS D. P. \& R.B. CALVALCANTI. 2001. Community similarity and abundance of bird species in open habitats of a central brazilian cerrado. Ornitología Neotropical 12: $57-73$.

WESTPHAL, M. I.; S.A. FIEL; A. J. TYRE; D. PATON; H.P. POSSINGHAM. 2003. Efects of landscape pattern on birds specie distribution in Mt. Lofty Ranges, South Australia. Landscape Ecology 18: 413-423.

WIENS, J. A. 1989. The Ecology of bird communities. Vol 1: Foundations and patterns. Cambridge, Cambridge University. 539p.

WIENS, J.A. \& J. T. ROTENBERRY. 1981. Censusing and the evaluation of avian habitat occupancy. Studies in Avian Biology 6:522-532.

WILLIS, E. O. \& Y. ONIKI. 1981. Levantamento preliminar de aves em treze áreas do estado de São Paulo. Revista Brasileira de Biologia 41 (1): 1221-135.

WILLIS, E. O. \& Y. ONIKI. 2003. Aves do estado de São Paulo. Rio Claro, Divisa. 400p.

WILLIS, E. O. 2004. Birds of a habitat spectrum in the Itirapina savanna, São Paulo, Brazil (1982-2003). Brazilian Journal of Biology 64 (4): 901-910.

ZAR, J. H. 1984. Biostatistical Analysis. Upper Saddle River (NJ), Pretice-Hall. 718p. 


\section{Anexo 1: Tabela com teste de Mann-Whitney}

Comparação entre os dados coletados nos anos de $2007(\mathrm{~N}=75)$ e $2008(\mathrm{~N}=34)$ para cada um dos componentes (variáveis) de micro-habitat por meio do teste de Mann-Whitney (teste U).

\begin{tabular}{lccc}
\hline \multicolumn{1}{c}{ Componentes do micro-habitat } & $\mathbf{U}$ & $\mathbf{Z}$ & $\begin{array}{c}\text { p-valor } \\
\text { (bilateral) }\end{array}$ \\
\hline Cobertura de capim nativo & 1268 & 0,0458 & 0,9635 \\
Cobertura de capim braquiária & 1258,5 & 0,1079 & 0,9141 \\
Cobertura de capim gordura & 1123 & 0,9942 & 0,3201 \\
Cobertura de solo exposto & 1248,5 & 0,1733 & 0,8624 \\
Cobertura de serapilheira & 1103 & 1,125 & 0,2606 \\
Número de subarbustos e arbustos com & 1144,5 & 0,8536 & 0,3933 \\
até 1 m de altura & & & 0,719 \\
Número de arbustos e arvoretas entre & 1220 & 0,3597 & \\
1,1 e 2 m de altura & & & 0,6589 \\
Número de árvores entre 2,1 e $4 \mathrm{~m}$ de & 1207,5 & 0,4415 & \\
altura & & & 0,64 \\
Número de árvores maiores que $4 \mathrm{~m}$ de & 1203,5 & 0,4677 & \\
altura & & & 0,9374 \\
Número de Syagrus petrea & 1263 & 0,0785 & 0,6518 \\
Número de Attalea geraensis & 1206 & 0,4513 & \\
\hline
\end{tabular}

